\title{
Characteristics of gravity waves resolved by ECMWF
}

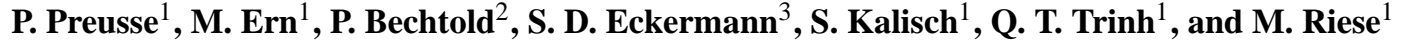 \\ ${ }^{1}$ Institute of Energy and Climate Research (IEK-7: Stratosphere) Forschungszentrum Jülich, Jülich, Germany \\ ${ }^{2}$ ECMWF, Reading, UK \\ ${ }^{3}$ Space Science Division, Naval Research Laboratory, Washington DC 20375, USA
}

Correspondence to: P. Preusse (p.preusse@fz-juelich.de)

Received: 23 February 2014 - Published in Atmos. Chem. Phys. Discuss.: 13 May 2014

Revised: 20 August 2014 - Accepted: 27 August 2014 - Published: 2 October 2014

\begin{abstract}
Global model data from the European Centre for Medium-Range Weather Forecasts (ECMWF) are analyzed for resolved gravity waves (GWs). Based on fitted 3-D wave vectors of individual waves and using the ECMWF global scale background fields, backward ray tracing from $25 \mathrm{~km}$ altitude is performed. Different sources such as orography, convection and winter storms are identified. It is found that due to oblique propagation waves spread widely from narrow source regions. Gravity waves which originate from regions of strong convection are frequently excited around the tropopause and have in the ECMWF model low phase and group velocities as well as very long horizontal wavelengths compared to other models and to measurements. While the total amount of momentum flux for convective GWs changes little over season, GWs generated by storms and mountain waves show large day-to-day variability, which has a strong influence also on total hemispheric fluxes; from one day to the next the total hemispheric flux may increase by a factor of 3. Implications of these results for using the ECMWF model in predicting, analyzing and interpreting global GW distributions as well as implications for seamless climate prediction are discussed.
\end{abstract}

\section{Introduction}

Despite the importance of gravity waves (GWs) for many atmospheric phenomena such as the quasi-biennial oscillation (Dunkerton, 1997; Ern and Preusse, 2009; Alexander and Ortland, 2010; Ern et al., 2014), the summer-time branch of the Brewer-Dobson circulation (Alexander and Rosenlof, 2003), the predicted acceleration of the winter-time branch of the Brewer-Dobson circulation due to global warming (McLan- dress and Shepherd, 2009; Butchart et al., 2010), as well as for the whole mesospheric dynamics, our knowledge on GWs is limited. This is mainly due to the fact that the effects of GWs are global, but that GWs are of small scales and mesoscales, and that even smaller scales are involved in their forcing, propagation and dissipation. In particular, for studying the interaction of GWs with the global circulation, general circulation models (GCMs) are required, in which GWs are not well represented (for overviews on GWs, their measurement and their implementation in global models see, for instance, Fritts and Alexander, 2003; Kim et al., 2003; Alexander et al., 2010 and Geller et al., 2013). There are two lines which can be followed for improving this situation: by enhanced understanding we may explicitly improve our representation of GWs in global models, or by enhanced resolution we may implicitly describe GWs correctly also on the global scale.

Chemistry climate models (CCMs), for instance, do not resolve GWs because of the missing spatial resolution of these models and the momentum transfer of GWs is therefore taken into account by submodels called GW parameterizations. This treatment in submodels is a major source of uncertainty and lack of realism for CCMs, evident by the design of the parameterizations: gravity waves excited by orography (mountain waves) are treated by a dedicated orographic parameterization (e.g., McFarlane, 1987; Lott and Miller, 1997). In most GCMs, GWs from all other sources are commonly treated in a second parameterization, which therefore is called non-orographic parameterization. The major difference between the two parameterizations is that the first considers zero ground-based phase speed GWs and the latter primarily waves with ground-based phase speeds distinct from zero. Non-orographic parameterization schemes 
assume a universal source spectrum of GWs. The spectrum is either completely homogeneous or depends only on latitude and is independent of longitude and time (season) (Hines, 1997; Warner and McIntyre, 1999; Medvedev and Klaassen, 2000; McLandress and Scinocca, 2005). Even the source altitude of the non-orographic parameterization schemes is uncertain; while some models assume sources above the tropopause (Becker and Schmitz, 2003; Senf and Achatz, 2011), most chemistry climate models use a launch height in the middle troposphere since wind filtering of the GW spectrum in the upper troposphere and lower stratosphere (UTLS) yields best agreement of the modeled GWs with global observations (Ern et al., 2006) and yields the best match of the middle atmosphere wind fields with climatologies (Manzini and McFarlane, 1998; Orr et al., 2010). Unphysical nonorographic schemes are unsatisfactory as GWs have localized sources causing longitudinal and temporal variations. In particular, the feedback of GW sources to climate change is, in these schemes, not represented.

In replacing the standard non-orographic schemes in CCMs by physical sources, progress is made for GWs excited by convection (e.g., Beres et al., 2005; Song and Chun, 2008; Richter et al., 2010). An overview of GWs from jets and fronts is given by Plougonven and Zhang (2014). Several processes are involved in the generation of GWs by jets and fronts. First, convection associated with the fronts is an important mechanism of GW generation (e.g., Fovell et al., 1992). This may be covered by the convective parameterizations. Second, GWs may be generated by a cross-front circulation and resulting isentrope oscillations (e.g., Griffiths and Reeder, 1996; Reeder and Griffiths, 1996) motivating Charron and Manzini (2002) to launch GWs from fronts in the cross-frontal direction. Third, GWs are generated in jet-exit regions which develop in baroclinic life cycles, as has been shown by O'Sullivan and Dunkerton (1995) and many follow-up studies (e.g., Plougonven et al., 2003; Zuelicke and Peters, 2006). Due to spontaneous adjustment (formerly called geostrophic adjustment) in consequence of baroclinic instability waves are emitted in the upper level jet. The wave vectors of these waves point roughly in the direction of the wind at the source location though different directions may occur at the edge of the jet (O'Sullivan and Dunkerton, 1995). Furthermore, there can be a positive feedback between the waves and diabatic heating by precipitation as suggested by Uccellini and Koch (1987). Parameterizations for the latter processes are still at a very early stage and not yet applicable in GCMs.

However, even for processes where source-based parameterizations are available, these parameterizations present new uncertainties: models may now contain more realism, but also a larger number of tunable parameters. For instance, there is increasing evidence (Ern et al., 2004; Wu and Eckermann, 2008; Hendricks et al., 2014; Plougonven and Zhang, 2014) that high GW momentum flux (GWMF) at winter high latitudes is generated to a large degree by spontaneous ad- justment and jet instability. However, this source is missing from the sources taken into account by the CCM simulations of Richter et al. (2010) and still the global distributions are realistic. This indicates that a different source in the model erroneously exerts the drag which in reality is exerted by the GWs generated by spontaneous adjustment.

A further simplification of all current GW parameterizations, except for the experimental setup of Song et al. (2007), is to assume that GWs propagate instantaneously and only inside the vertical column. This simplification is made despite evidence that oblique propagation influences the distribution of GWMF and drag on the global scale (Jiang et al., 2004b; Watanabe, 2008; Preusse et al., 2009a; Sato et al., 2009; Choi et al., 2009; Ern et al., 2011, 2013; Kalisch et al., 2014) because this implementation allows for effective parallelization of the GCM code.

Despite first attempts to replace the unphysical nonorographic sources by physics-based source parameterizations, clearly there is still much work to do. First, the current set of physics-based sources is likely to be incomplete. Second, the theoretical formulation of these sources is simplified and needs validation, and third, these formulations have free, tunable parameters. For instance, the relative importance and dominant horizontal wavelengths of different sources are still poorly constrained and largely unknown. Attempts to include ray-tracing $\mathrm{GW}$ parameterizations lead to numerically expensive models. At the same time computers are becoming more powerful and spatial resolution is permanently increasing. This leads to the following question: do we need to develop parameterizations further or will in future highly parallelized high-resolution models solve all the problems implicitly?

In a new concept of seamless prediction it is envisaged to develop climate models based on weather forecast models or, more precisely, numerical weather prediction (NWP) models. Weather forecasting requires high spatial resolution. Parameterizations for some still non-resolved processes such as precipitation are developed by larger teams than available for middle atmosphere models and validated in the use of weather forecasts. One of the most advanced NWP systems is developed and operated at the European Centre for MediumRange Weather Forecasts (ECMWF). The spatial resolution of the ECMWF general circulation model in 2008 was T799, L91 corresponding to a spatial sampling of $25 \mathrm{~km}$ and has increased since (at the time of writing the actual version is Cy40r1, which was implemented in November 2013 and has a resolution of T1279, L137). This resolution should be sufficient to resolve a larger part of the GW spectrum. Being thus a precursor for a GW resolving global GCM we can ask the following questions: what are the various sources for GWs in the middle atmosphere in the ECMWF model? What can we learn about their relative importance and variability? And do GWs in ECMWF data have realistic properties?

Despite the fact that a large part of the GW spectrum is resolved in the model, the ECMWF model needs to rely on 
a GW parameterization for a realistic representation of the middle atmosphere (Orr et al., 2010). This differs from some general circulation models (GCMs) with a comparable horizontal resolution which produce a tropical oscillation similar to the quasi-biennial oscillation (QBO) and even realistic global wind and temperature patterns in the mesosphere without any parameterized GW drag (Hamilton et al., 1999; Watanabe, 2008; Kawatani et al., 2010). These differences show that also GWs resolved in models need validation, as is shown by Geller et al. (2013).

The question to which degree GWs are represented realistically in ECMWF data is important as well for other applications. In addition to weather forecasts, analyses of ECMWF are used as input for many scientific studies. In this way gravity waves resolved by the ECMWF model could influence also cloud formation and chemistry in trajectory studies or chemistry transport models.

For ECMWF data a number of studies comparing resolved GWs with measurements and other models exist. Gravity wave structures above a typhoon are investigated by Kim et al. (2009). They compare ECMWF data with the results of a mesoscale model and observations: the ECMWF model estimates overly long wavelengths and underestimates the amplitudes, but in general observed and modeled structures are similar. Mountain waves are investigated in a case study for the Norwegian Alps (Eckermann et al., 2006) and ECMWF model data show broadly realistic features with respect to nadir-viewing satellite observations.

Many papers discuss GWs from jets and fronts. For instance, Moldovan et al. (2002) and Plougonven and Teitelbaum (2003) investigate radiosonde measurements from the Fronts and Atlantic Storm-Track EXperiment (FASTEX; Joly et al., 1997). They find wave structures similar to those observed by radiosondes also in the ECMWF temperature and horizontal wind divergence fields. Hertzog et al. (2001) interpret lidar measurements of a GW by backward ray tracing. They conclude that spontaneous adjustment close to tropopause altitudes is the most likely source. This is caused by baroclinic activity, as in the case studies by O'Sullivan and Dunkerton (1995). In the likely source region they also find GW signatures in horizontal wind divergence fields from ECMWF. Tateno and Sato (2008) investigate the source of two waves observed by the Shigaraki radar, also by ray tracing. They found indication for GW excitation by spontaneous imbalance in the jet southward of the observation site and comparable waves in the ECMWF fields.

Variations of GW potential energy during the 2009 stratospheric sudden warming are investigated by Yamashita et al. (2010) on the basis of ECMWF global fields. In order to assess the realism of these variations the ECMWF data are compared to several-year climatologies of GW potential energy inferred from lidar data at Rothera and at the South Pole. In addition, GW potential energies from GPS radio occultations for the latitude range $65^{\circ} \mathrm{N}$ to $70^{\circ} \mathrm{N}$ are compared in a 30-day time series. In both cases the magnitude and tem- poral variations agree very well. However, the temporal removal of the background is based on a shorter integration time for the lidar, and for the GPS data the observational filter (Preusse et al., 2002; Lange and Jacobi, 2003) is not taken into account. This means that, if potential energy from ECMWF were inferred in the same way as in the observations, ECMWF would be lower and, as a consequence, this may indicate too low GW potential energy in ECMWF.

Shutts and Vosper (2011) find good correspondence between global distributions of GWMF from the ECMWF model and from High Resolution Dynamics Limb Sounder (HIRDLS) observations (Alexander et al., 2008). Since Alexander et al. (2008) also does not correct for observational filter effects, this also is indication for some underestimation of the GWMF resolved by the ECMWF model (for a detailed discussion of observational filter effects for GWMF from infrared limb sounding see Ern et al., 2004). Furthermore, Shutts and Vosper (2011) note an underestimation of GWMF at low latitudes where convection is the most important source.

In a systematic survey Schroeder et al. (2009) compares GW signatures in ECMWF data with GW amplitudes from the infrared limb sounder SABER (Sounding of the Atmosphere Using Broadband Emission Radiometry). The results indicate that amplitudes are generally too low in ECMWF data. Very good temporal and spatial correlations between the SABER observations and ECMWF model data are found for prominent mountain wave regions such as Tierra del Fuego and the Norwegian Alps, but only moderate correlations are found for regions where previous studies indicate prominent convective excitation of GWs, for instance for the Gulf of Mexico or for the region of the Asian monsoon (Preusse et al., 2001; Jiang et al., 2004b; Wright and Gille, 2011; Ern et al., 2011). Large values of the correlation coefficient are caused by strong, temporally corresponding variations in the time series of measurements and model. These strong variations are observed over orographic source regions (Eckermann and Preusse, 1999; Jiang et al., 2002; Schroeder et al., 2009; Plougonven et al., 2013). Individual convective sources are also highly intermittent, but averaged over specific convective source regions such as the Asian monsoon, convection and convective GWs are active in the Northern Hemisphere for the whole period July to September with only small variations. The moderate correlation values for convective source regions in Schroeder et al. (2009) may therefore be simply due to the fact that variations are too small and infrequent. They could also be, however, indication of a shortcoming in the ECMWF model. Further evidence is needed to answer this question.

A global GW resolving model such as the ECMWF model always contains GWs from many different sources. However, scientific understanding is based on the understanding of the individual source processes. Also the importance of still-missing resolution or of other parameterizations for the excitation of GWs depends on the source process. Therefore 
we have the following major aims in this paper: (1) identify the various source processes from a global distribution, (2) estimate the relative importance of different sources for the total GWMF, and (3) assess whether the waves from these sources are realistic. The first step is the basis of the other two, of course, and in the lack of better means it is frequently performed by spatial co-location of tropospheric sources and stratospheric wave events. This, however, can be very misleading, as shown in this study. A better method is therefore required and we use single-wave identification and backward ray tracing.

Our work is based on a study in support of a proposed infrared limb-imaging satellite instrument (ILI) (Riese et al., 2005; Preusse et al., 2009b), which would be capable of measuring 3-D distributions of temperatures at a sufficient spatial resolution to resolve GWs. The study was designed to assess the accuracy of the GWMF which can be inferred from such data, and to demonstrate the scientific advance promised by the novel measurements. Since the analysis fully characterizes GWs resolved by the ECMWF model in terms of amplitudes, momentum flux and the 3-D wave vector, it provides an ideal data base for our current studies of ECMWF GW sources based on back-tracing single waves. Sampling the model by the ILI measuring tracks does not affect the generality of the results.

In this paper we will use backward ray tracing to identify the main sources for the GW distribution in the lower stratosphere. We will show examples for mid and high latitudes as well as for GWs in the tropics. In Sect. 2 we will describe the ECMWF data, the method to identify and quantify GWs in these data and how this can be used to identify the sources by backtracing. In Sect. 3 we will first apply these methods globally to sample data from a single day, 29 January 2008, and investigate various sources such as orography and convection from the global distribution. We then focus on tropical GWs (Sect. 4) and first introduce concepts developed in previous work (Sect. 4.1). We show the relation between GWs and convection and discuss the excitation altitude (Sect. 4.2), and determine the spectral properties which are compared to other models and measurements (Sect. 4.3). Sources at higher latitudes are discussed in Sect. 5. Currentday observations have insufficient data density and precision (considering GWMF) to investigate short-term variations of e.g., hemispheric total fluxes. Here ECMWF data can give valuable insight (Sect. 6). Finally, we summarize the results and discuss their meaning for using ECMWF data in GW research and for approaches of seamless weather prediction.

\section{Data, analysis and ray tracing}

In this paper, five periods, each of 7-days length, are presented; the data are for January, April, July, August and September 2008. Selection criteria were (a) to create data representative of both solstices, i.e., Northern Hemisphere

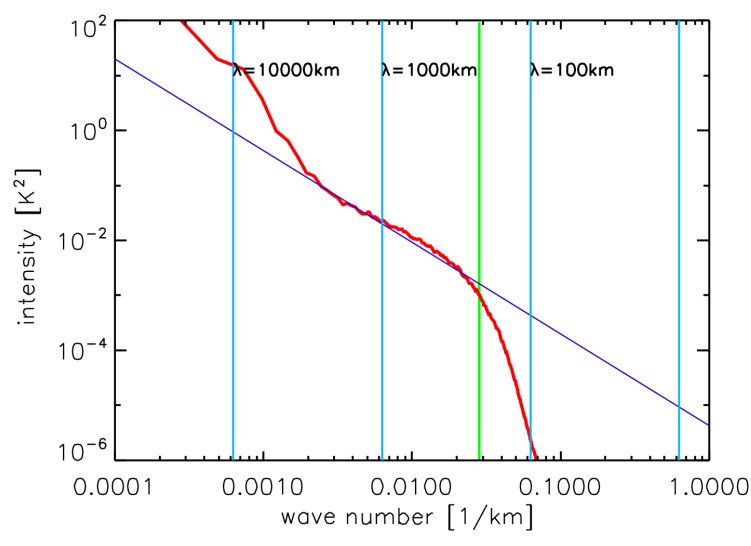

Figure 1. Power spectra of ECMWF temperatures in zonal direction averaged over the period from 28 January to 3 February 2008 and over latitudes from 40 to $60^{\circ} \mathrm{N}$. Altitude is $25 \mathrm{~km}$. The red line shows the average power spectral density in $\left[\mathrm{K}^{2} \mathrm{~km}\right]$, the purple line indicates a slope of $-5 / 3$, the green line indicates the fitby-eye where the spectrum becomes significantly steeper than the power-law, corresponding to a wavelength of $\sim 220 \mathrm{~km}$. Vertical blue lines are drawn for horizontal wavelengths of 10, 100, 1000 and $10000 \mathrm{~km}$.

summer and winter, as well as equinox conditions, and (b) high mountain wave activity in the polar vortices for the respective winter cases.

\subsection{ECMWF data}

We consider temperature forecast data from the ECMWF model (Persson and Grazzini, 2005) with a resolution of T799 L91. Due to data assimilation, the model represents well the global and synoptic state of the real atmosphere. Mesoscale dynamics such as GWs are generated by the GCM in a self-consistent manner. The presence of GWs in the data therefore depends on two conditions. First, the model must contain the processes which excite GWs, such as flow over orography, convection or flow instability. Second, the model must have sufficient resolution to allow the generated waves to persist and propagate.

The spectral resolution of the ECMWF-GCM would allow to resolve GWs with horizontal wavelengths as short as $50 \mathrm{~km}$, but in order to gain numerical stability, the shortest scales are damped by hyper-diffusion. We here apply the method of Skamarock (2004) in order to estimate the effective resolution of the ECMWF data. For this, we calculate power spectra of temperatures along latitude circles. Figure 1 shows in red the average of all spectra over the period 28 January 2008 to 3 February 2008 and latitudes between $40^{\circ} \mathrm{N}$ and $60^{\circ} \mathrm{N}$. The individual spectra were calculated by means of a one-dimensional Fourier-transform for a fixed latitude and time. The ECMWF data we use are on a grid of constant longitude spacing. We neglect the resulting variation of the horizontal sampling distance with latitude for the averages 


\section{Jan. 2008, 12:00 GMT ; 25 km altitude}

a)
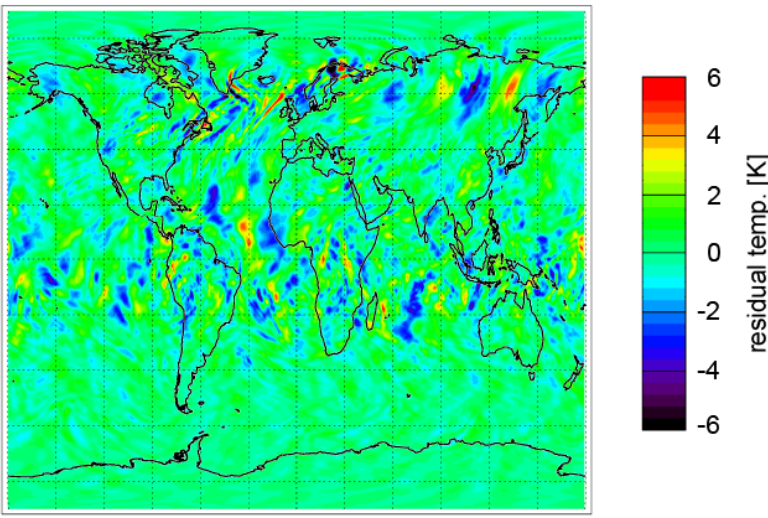

c)

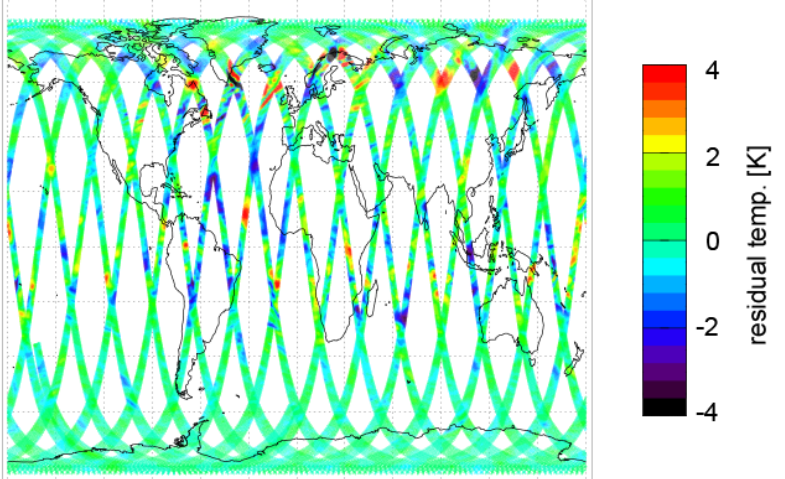

b)

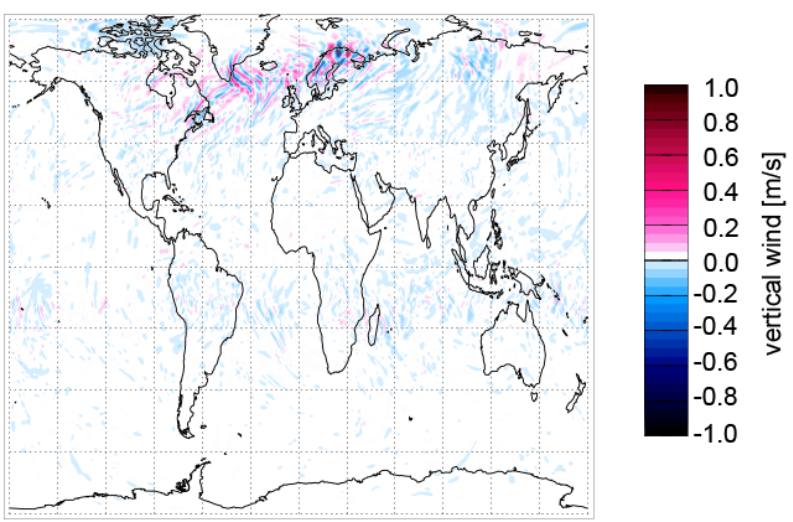

d)

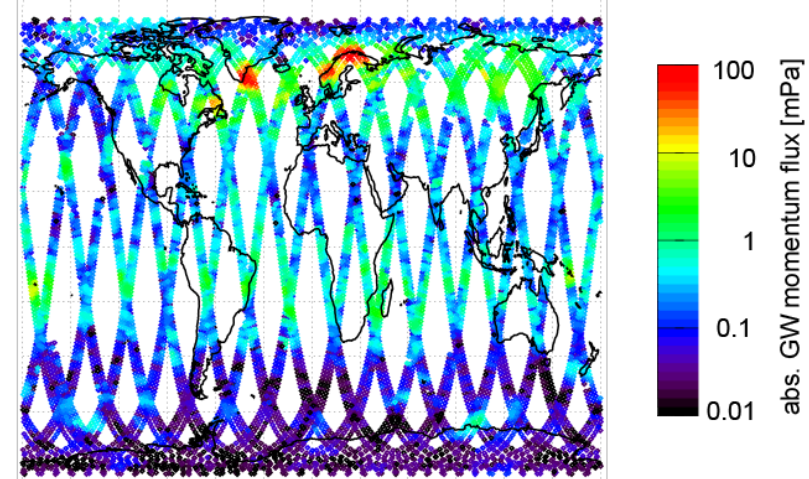

Figure 2. Gravity wave parameters in ECMWF reanalysis fields. Panel a shows temperature residuals from black, $-6 \mathrm{~K}$ to red, $6 \mathrm{~K}$ after removing the zonal mean and planetary scale waves up to wave-number 6 . Vertical winds (blue, $-1 \mathrm{~m} \mathrm{~s}^{-1}$ to red, $+1 \mathrm{~m} \mathrm{~s}^{-1}$ ) in (b) highlight the small-scale structures. For satellite-like processing the residual temperatures (black, less-equal than $-4 \mathrm{~K}$ to red, larger-equal $4 \mathrm{~K}$ ) are sampled to simulated measurement positions of an ILI in (c). After applying a limited-volume three-dimensional sinusoidal fit, GW momentum flux (black, less-equal $0.01 \mathrm{mPa}$ to larger-equal $100 \mathrm{mPa}$ ) is deduced $(\mathbf{d})$. GWMF is largest in regions of strong vertical wind structures (b) and where temperature residuals indicate large amplitudes of short horizontal scales (a, c).

and use the wavelength values corresponding to a latitude of $50^{\circ} \mathrm{N}$. The purple line indicates a slope of $-5 / 3$. According to turbulence theory, dynamical variables such as horizontal winds and temperatures should obey a scaling law with an exponent between -2 and $-5 / 3$ in the dependence on intrinsic frequency or horizontal wave number. This is corroborated by observational data (e.g., Bacmeister et al., 1996; Eidmann et al., 2001; Hertzog et al., 2002). The ECMWF data show this behavior for horizontal wavelengths longer than about $220 \mathrm{~km}$ (corresponding to $0.028 \mathrm{~km}^{-1}$, green line). At horizontal wavelengths shorter than $\sim 220 \mathrm{~km}$ a steep decrease is observed. Since we expect the scaling law to hold for even much shorter scales in nature, this indicates the artificial decrease due to strong dissipation in the model, which uses a semi-Lagrangian advection scheme. It should be further noted that waves shorter than $100 \mathrm{~km}$ have vanishing amplitudes. Corresponding investigations for high latitude $\left(60^{\circ}\right.$ to $80^{\circ}$ ) and the tropics (equatorward of $20^{\circ}$ ) indicate that waves with wavelengths longer than 180 and $300 \mathrm{~km}$, respectively, are properly resolved by the GCM.

\subsection{Data analysis}

Figure 2 illustrates the various steps of processing applied to the data. In order to isolate GWs, a global-scale background consisting of the zonal mean and planetary scale waves with zonal wave numbers 1-6 (Ern et al., 2011) is subtracted by means of a Fourier transform. Resulting temperature residuals (panel a) for 12:00 GMT of the respective day are sampled to the observation locations of the ILI (panel c). Between $82.7^{\circ} \mathrm{S}$ and $82.7^{\circ} \mathrm{N}$, data will be taken on 15 orbits per day with a sampling of $50 \mathrm{~km}$ along-track, $30 \mathrm{~km}$ across-track in 12 tracks and $700 \mathrm{~m}$ in the vertical from 5 to $50 \mathrm{~km} .{ }^{1}$ These interpolated data shown in panel

\footnotetext{
${ }^{1}$ Please note that we only interpolate to a different grid and do not perform a full instrument simulation. Therefore, the sampled
} 
$\mathrm{c}$ therefore adequately sample the shortest waves present in ECMWF data. Sinusoidal fits (Lehmann et al., 2012) are performed in sub volumes of $350 \mathrm{~km} \times 360 \mathrm{~km} \times 10 \mathrm{~km}$ alongtrack $\times$ across-track $\times$ vertical. New fits are performed every $150 \mathrm{~km}$ (every third point) along track. The resulting temperature amplitudes and wave vectors are allocated to the cube center. The method is capable of characterizing also waves with horizontal and vertical wavelengths larger than the fit volume. The vertical flux of horizontal pseudomomentum (in short gravity wave momentum flux; GWMF) is calculated from wave vector and temperature amplitude (Ern et al., 2004) via

$\left(\boldsymbol{F}_{p x}, \boldsymbol{F}_{p y}\right)=\frac{1}{2} \rho \frac{(k, l)}{m}\left(\frac{g}{N}\right)^{2}\left(\frac{\hat{T}}{\bar{T}}\right)^{2}$,

where $\left(\boldsymbol{F}_{p x}, F_{p y}\right)$ is the horizontal vector of the vertical flux of GW pseudomomentum, $(k, l, m)$ defines the wave vector, $\hat{T}$ is the wave amplitude, $\bar{T}$ is the background temperature, $g$ is Earth's acceleration and $N$ is the buoyancy frequency. It is shown by Lehmann et al. (2012) that fitting two sinusoids in small volumes represents well both total GWMF as well as spectral distribution of GWMF in a given region compared to Fourier analysis of the same region.

Gravity wave momentum flux values for the cube centers on the ILI tracks are shown in Fig. 2d. Note that maxima of GWMF are strongly localized and that GWMF varies over more than 3 orders of magnitude, globally. Maximum GWMF is observed for the southern tip of Greenland and over Norway.

Vertical winds at full model resolution are shown in Fig. 2b. Vertical winds emphasize GWs with short periods and short horizontal wavelengths which carry largest GWMF. Accordingly, no background is subtracted for Fig. 2b. Comparing the different panels, we find that large GWMF in Fig. 2d is indicated for the same location where Fig. $2 b$ shows large vertical winds and that for these locations large amplitude, short horizontal wavelength structures are found in the temperature maps in Fig. 2a and c.

The precision of the individual fits is estimated by statistically comparing GWMF calculated from temperatures with GWMF based on model winds. For the latter, the wave vector was fitted based on the vertical winds, the amplitude is fitted for all three wind components individually. By correlation analysis we find very good correlation (usually better than 0.9 for 4000 points at each day), a scatter of $10 \%$ to $15 \%$ width and a general low bias of temperature-based GWMF in the order of $25 \%$. A precision of $15 \%$ or better for the individual values is compatible with the study of Lehmann et al. (2012) using data generated by the Weather Research and Forecasting (WRF) model, the bias seems to be a feature innate to the ECMWF model. An example showing a common correlation for 34 test days and $25 \mathrm{~km}$ altitude is shown

data still retain the characteristics of ECMWF data and do not contain additional noise and are not affected by an observational filter. in Appendix A. The good correspondence between GWMF from temperature and winds also confirms that the majority of analyzed mesoscale events obey the polarization relation of GWs, and that therefore the implicit assumption that the majority of these structures are due to GWs is correct.

The finite-volume three-dimensional sinusoidal fits (S3D) determine the properties of monochromatic waves, and in this study we focus on the most prominent wave structure in each investigated 3-D volume. Since we determine the 3-D wave vector and the amplitude and associate these wave parameters with the centers of the fitting cubes, the waves are fully characterized. This allows us to backtrace the waves to potential source locations using the Gravity Wave Regional or Global Ray Tracer (GROGRAT; Marks and Eckermann, 1995). The GROGRAT ray tracer is based on the dispersion relation for GWs

$\hat{\omega}^{2}=\frac{\left(k^{2}+l^{2}\right) N^{2}+f^{2}\left(m^{2}+\frac{1}{4 H^{2}}\right)}{k^{2}+l^{2}+m^{2}+\frac{1}{4 H^{2}}}$,

where $\hat{\omega}$ denotes the intrinsic frequency as seen by an observer moving with the background wind, and $H$ gives the density scale height. From the dispersion relation the intrinsic group velocity is calculated by partial derivatives, e.g., $\hat{c}_{g, x}=\partial \hat{\omega} / \partial k$. Since a wave packet propagates in the direction of its group velocity, this allows to determine the new location of this wave packet after a chosen time step. According to the ray-tracing equations (Lighthill, 1978) new horizontal and vertical wave numbers $(k, l, m)$ for the new position are calculated from the gradients of the background wind fields. This process is iterated until the wave either hits a boundary or becomes non-propagating, e.g., due to reaching a critical level. Stepping backward in time instead of forward, a ray can be backtraced.

Ray tracing calculates the refraction of waves due to vertical and horizontal gradients in the background wind fields and the buoyancy frequency. Background wind fields for ray tracing should contain all synoptic-scale structures, but not finer scale GWs, since otherwise the ray (which is a pointrepresentation of a finite-extent wave packet) would react to the local gradients caused by the same GWs we are investigating. Therefore, and for reasons of computational cost, background wind fields of reduced resolution were obtained from ECMWF. These were interpolated on a grid of $2.5^{\circ}$ latitude, $3.75^{\circ}$ longitude and $\sim 2.5 \mathrm{~km}$ altitude for use in GROGRAT. We also neglect temporal changes of the wind fields and use snap-shots for the time when the wave is identified in the stratosphere along the whole wave trajectory.

The end point of a backward ray is not necessarily the source of the GW. Waves are traced back until they either approach a critical level, the ground is reached, or the rays leave the lateral boundary at either $85^{\circ} \mathrm{S}$ or $85^{\circ} \mathrm{N}$. While the latter condition is technical, the first two conditions are physical. For instance, a critical level means that at this altitude the ground-based phase speed of a wave equals the wind 
a)

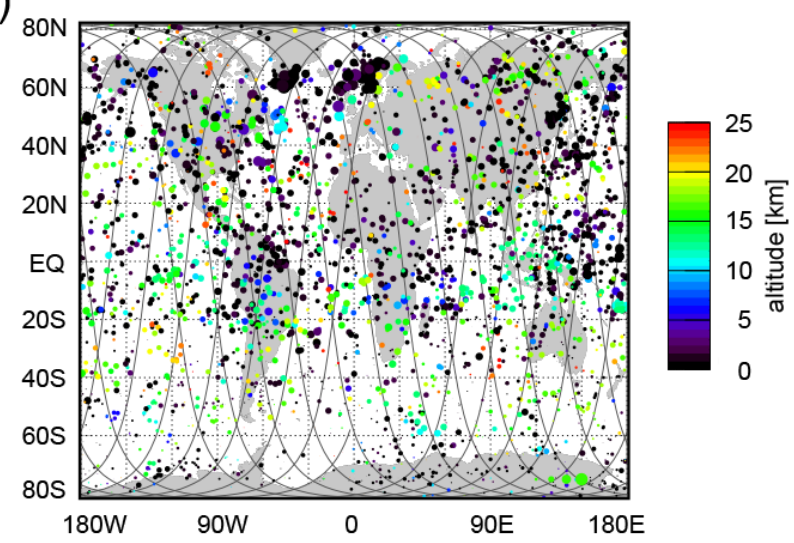

c)

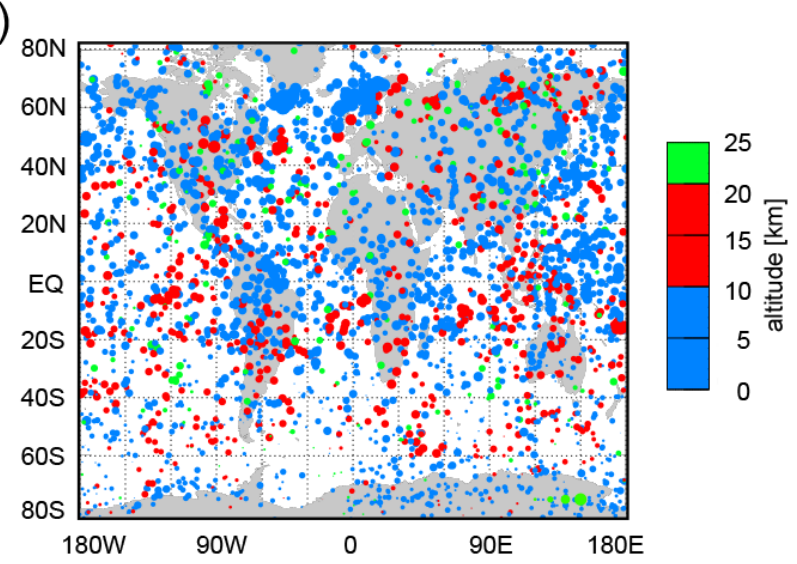

b)

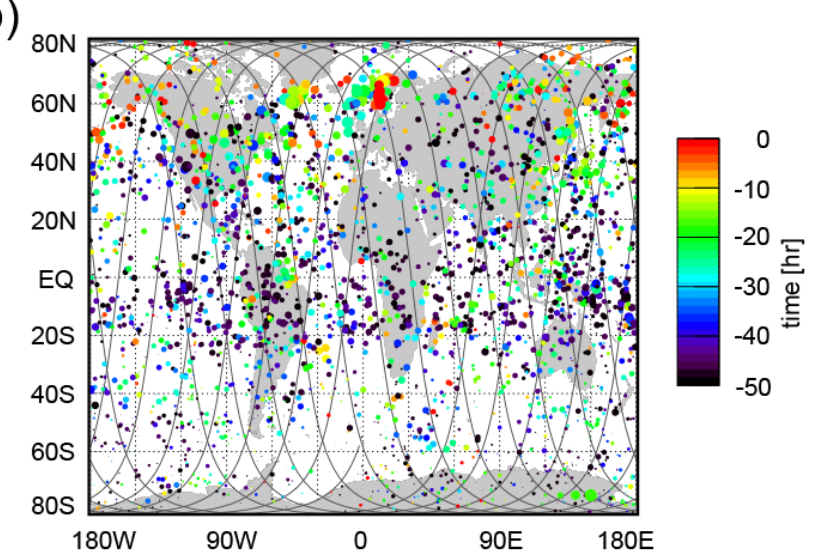

d)

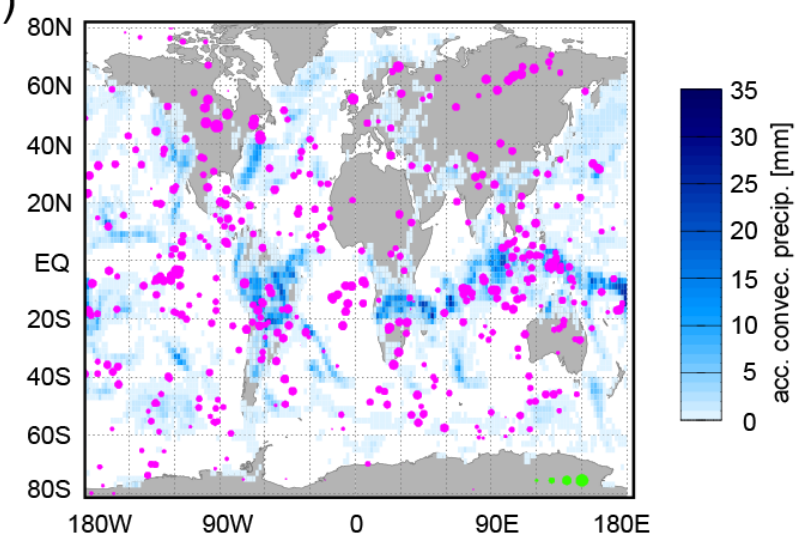

Figure 3. Global maps of (a) the ray-termination location and the altitude $[\mathrm{km}]$ to which rays can be backtraced (lowest traceable altitude: LTA) for 29 January 2008, (b) the time to reach the ray termination in hours, (c) altitude, as (a), but with reduced color scale and (d) only the rays which terminate between $12 \mathrm{~km}$ and $18 \mathrm{~km}$ altitude overplotted on accumulated precipitation [mm] for 27 January. Precipitation is smoothed by a box-average of $9 \times 9$ points. The size of the dots is a measure of the GWMF at $25 \mathrm{~km}$ altitude. In order to determine the value, please refer to the green dots in the lower right corner of the panels which indicate $0.01,0.1,1$ and $10 \mathrm{mPa}$, respectively (scale is equal for all panels). In panel (b) black indicates $50 \mathrm{~h}$ or more.

velocity, in which case the vertical wavelength of the wave vanishes according to Eq. (2). The source of the wave hence cannot be below the critical level, because the wave would dissipate in propagating upward, but it also cannot be exactly at the critical level, because there the wave has vanishing amplitude (the saturation amplitude is proportional to the vertical wavelength). Therefore the wave is generated by a source process above the critical level and located somewhere along the trajectory. If backtraced to the ground, the source can be at the ground, e.g., for waves caused by flow over orography, but for instance for convective waves we would expect the source inside the convective cloud and above ground. In principle, the wave source therefore can be at any altitude above the lowest traceable altitude (LTA), but not below the end point of the ray ${ }^{2}$.

\footnotetext{
${ }^{2}$ It should be noted in this context that in nearly all cases where the rays are terminated above ground the reason is that the traced GWs approach a critical level from above. In this case, the vertical
}

Unfortunately, backtracing does not provide us with a unique solution for the wave amplitude at LTA level. In general, wave action conservation predicts that GW amplitudes grow when the waves are propagating upward into less dense air. However, if the wave reaches its saturation amplitude, it partly dissipates and stalls growing in amplitude. For these waves it is impossible to infer which amplitude they would have at source level. In the discussion below, we therefore consider the momentum flux at the "observation" altitude of $25 \mathrm{~km}$.

wavelength of a GW becomes small and a supposed vertical wave packet assumes a small vertical extent compatible with a well defined altitude. This will become relevant in particular in Sect. 4.2 where we discuss GW excitation around the tropopause. 


\section{Results for 29 January 2008}

In Sect. 2 we introduced a method to screen a data set systematically for potential sources. In this section we apply this method to the example of a single day, 29 January 2008. By the example of this single day we investigate which information can be taken immediately from the pattern of backtraced potential ray origins.

Global backtracing data from 1 day are presented for the example of 29 January 2008, 12:00 GMT in Fig. 3. The dark gray traces in panels a and b show the ILI "measurement" tracks from where the ray traces are launched at $25 \mathrm{~km}$. For each analysis result from the finite-volume three-dimensional sinusoidal fits (S3D) a ray is initialized. In this way backtraces are launched every $150 \mathrm{~km}$ along the track. The waves likely originate from or close to the locations where the rays terminate and which therefore are called in brief wave origins below. They are indicated by dots in Fig. 3. In Fig. 3a the color of the dots indicates the altitude of the ray termination (LTA). Since we are performing backward ray tracing, the time elapsed between launch at the measurement and ray termination is negative. The elapsed time is shown in Fig. 3b. For waves of similar group velocities, one would expect that GWs of lower LTA need more time to propagate. However, checking the maps in detail one finds short times (red and green in panel b) frequently for waves from lower tropospheric sources (black and blue in panel a), while many waves with high LTA have long propagation times. Accordingly, propagation time in these maps is mainly an indicator of vertical group velocity. Fast waves, which propagate only a short time between source and observation altitude, are represented by red, slow waves which require up to 2 days and more are shown in blue and black. The diameter of the dots is proportional to the base- 10 logarithm of the momentum flux of the individual GWs at $25 \mathrm{~km}$ altitude, and the green dots in the lower right corner (same in all panels) indicate 10, 1 , 0.1 and $0.01 \mathrm{mPa}$, respectively.

Inferring GWMF values at equal distances along the track provides a statistical measure of the GWMF per unit area for the analysis altitude of $25 \mathrm{~km}$. This is independent of the fact that in this way some wave events may be sampled by several analysis cubes. In the same way, the density of rays or ray origins in a certain region combined with the GWMF magnitude associated with the individual rays provides a measure for the effectiveness of source regions with respect to the GWMF at the analysis altitude.

The most prominent source regions on the globe are two clusters of wave origins at the southern tip of Greenland and west of the Norwegian coast. The location of the wave origins around Greenland is compatible with excitation of GWs by flow over orography; the wave origins around Norway, however, extend far into the ocean. In order to investigate the source of these waves more closely we show horizontal winds in the lower troposphere at $850 \mathrm{hPa}$ in Fig. 4a. Colors indicate the absolute wind velocity, the arrows the wind direction. Since Fig. $3 b$ indicates that most waves offshore of Norway require somewhat less than 1 day from LTA to observation altitude, winds are given for 28 January, 18:00 GMT, that is $18 \mathrm{~h}$ prior to the stratospheric GWs. At this time a strong storm with maximum wind velocities exceeding $30 \mathrm{~ms}^{-1}$ is approaching the Norwegian coast. Some streaks of high wind velocities connected with this storm are seen southward of the storm center, over the Northern Sea and to the coast of Scotland. Figure $4 \mathrm{~b}$ reproduces the wave origins and LTA from Fig. 3 for this region. The wave origins are located along the largest wind velocities in Fig. 4a. In addition, panel $\mathrm{b}$ shows the horizontal wind divergence $\frac{\partial u}{\partial x}+\frac{\partial v}{\partial y}$, which is frequently used as a suitable indicator for GWs.

The strongest wave signatures in the divergence fields in Fig. $4 \mathrm{~b}$ are waves in the lee of Greenland and above the southern tip of Norway (the latter marked by a red ellipse, labeled 1). The most likely source for these waves is flow over orography in these regions. These waves are clearly identified by the ray tracer. Along the shore line of northern Norway wave origins mark waves which seem to be generated slightly upstream of the orography (marked by a red ellipse labeled 2). West of these two ellipses, orography cannot be the source of the waves: less pronounced than the orographic waves but much larger in area are wave signatures collocated with the maximum wind velocities. It should be noted that the wave fronts of these waves are oriented southwest to northeast, i.e., they are at an angle (and not perpendicular) to the chiefly westerly winds. Due to this orientation and also given their long horizontal wavelengths they are expected to propagate far downstream. Testing this (not shown), we find that waves from the storm spread downstream as far as $60^{\circ}$ in longitude and down to the Ural mountains. In particular, the offshore storm is the source of the high GWMF values in northern Norway, which by pure collocation would likely have been interpreted as mountain waves.

Following Hertzog et al. (2001) we consider the wave parameters along the backward trajectory of these largest events "observed" over northern Norway at $25 \mathrm{~km}$ altitude. In several parameters, that is vertical wavelength, GWMF and WKB ${ }^{3}$ parameter (Marks and Eckermann, 1995) we find a maximum in the altitude range $4-7 \mathrm{~km}$. Also the wave attains a much slower vertical group velocity below this altitude. Hertzog et al. (2001) interpret this as evidence that the "true" source of the wave is close to the altitude of this peak, i.e., in our case around $5 \mathrm{~km}$ in the mid to upper troposphere. Further evidence is that below $5 \mathrm{~km}$ the horizontal wavelength decreases and assumes a value of less than $200 \mathrm{~km}$ at $4 \mathrm{~km}$

\footnotetext{
${ }^{3}$ The standard theory of GWs is based on the assumption that the variation of the background field is small within one wavelength and one wave period. This assumption is named after Wentzel, Kramers and Brillouin and called WKB assumption. In GROGRAT this is quantified by a WKB parameter, which remains smaller than 1 where the assumption is valid. For details see Marks and Eckermann (1995).
} 
a)

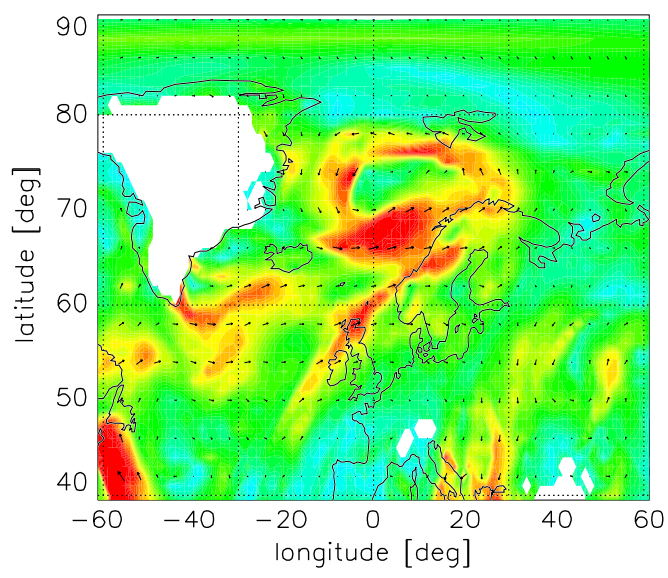

b) rays from 29-Jan $12: 00 ; 25 \mathrm{~km}$ wind div.: $28-J a n 18: 00 ; 5 \mathrm{~km}$

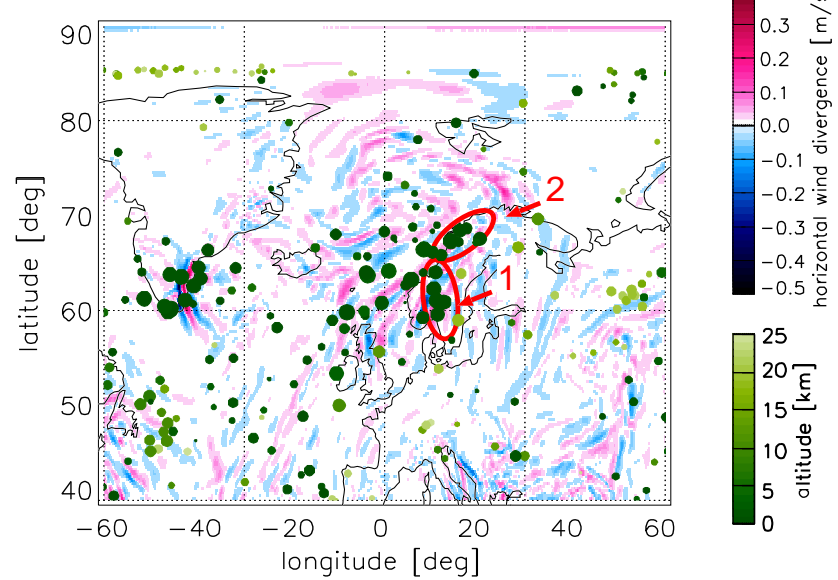

Figure 4. Absolute horizontal wind velocities (blue, $0 \mathrm{~m} \mathrm{~s}^{-1}$ to red, larger-equal $30 \mathrm{~m} \mathrm{~s}^{-1}$; arrows indicate direction) at $850 \mathrm{hPa}$ (a) for the North Atlantic. Values given are $18 \mathrm{~h}$ prior to the GWMF analyses shown in Figs. 2 and 3 and display a storm approaching the Norwegian coast. Horizontal wind divergence (blue, $-0.5 \mathrm{~ms}^{-1} \mathrm{~km}^{-1}$ to red, $0.5 \mathrm{~ms}^{-1} \mathrm{~km}^{-1}$ ) for the same time (b) indicates GW activity at the south tip of Greenland, in the high-wind regions over the Northern Sea and for the southern part of Norway. The southern part of Norway is indicated by the red ellipse marked " 1 ". Also along the coast of mid Norway (red ellipse marked " 2 ") some wave structures are seen. These regions are source of strong $\mathrm{GW}$ activity at $25 \mathrm{~km}$, as indicated by the backtraces (altitude-colored dots; dark green, $0 \mathrm{~km}$ to light-green, $25 \mathrm{~km})$.

altitude and of only $100 \mathrm{~km}$ close to the ground. This is below the resolution of the model, i.e., the wave could not have existed at altitudes below $\sim 4 \mathrm{~km}$ and must be generated above in the ECMWF model.

The waves with ray origins over the open sea are clearly related to the approaching storm system and hence related to excitation by jets and fronts as described by Plougonven and Zhang (2014) and briefly mentioned in the introduction. The case is very similar to the one described by Hertzog et al. (2001) and spontaneous adjustment is the most likely source process. Because the true source is at a higher altitude also the location is not identical with the ray origins shown in Fig. $4 \mathrm{~b}$ but closer to the Norwegian coast. In this region we find coherent wave crests. While this is clearly not a mountain wave, the orography of the Norwegian alps may play an indirect role in the generation of the wave.

The generation of GWs by storms merits further consideration. In particular, implementing an algorithm identifying automatically peaks in the ray-traced parameters, one may actually infer in a systematical way the true source location instead of the location of the ray termination. This could also provide further valuable input to the investigation of the storm system. This, however, is beyond the scope of this paper.

At low latitudes $\left(40^{\circ} \mathrm{S}-40^{\circ} \mathrm{N}\right)$ Fig. 3 shows moderate GWMF, and GW backtraces form no obvious source clusters. In the LTA, however, patterns can be recognized and the rays seem to cluster in color rather than in location. In order to show this more clearly we have replotted Fig. 3a with a simplified color scale in Fig. 3c. Blue is indicating tropo- spheric, red UTLS and green stratospheric LTA. Red dots are particularly frequent in the southern subtropics $\left(20\right.$ to $\left.10^{\circ} \mathrm{S}\right)$, in a diagonal stripe from $150^{\circ} \mathrm{E}, 20^{\circ} \mathrm{S}$ to Florida, and above the maritime continent (Indonesia and other tropical islands between $90^{\circ} \mathrm{E}$ and $150^{\circ} \mathrm{E}$ ). In the southern summer we expect the maximum of precipitation around $10^{\circ} \mathrm{S}$ above the continents and above the maritime continent. This seems to indicate a connection between high LTA and convection. In order to pursue this further, we show wave origins for only those waves with LTA between $12 \mathrm{~km}$ and $18 \mathrm{~km}$ together with precipitation for 27 January, 12:00 GMT, smoothed by a box average of $9 \times 9$ points. We choose precipitation 2 days previously to the "observations", since black to purple are the most frequent colors in the tropics in Fig. $3 \mathrm{~b}$ indicating a propagation time of around 2 days. We observe a general spatial co-location between potential wave source locations in the UTLS and regions of enhanced convection. The purple dots follow, for example, the arc-like structure of precipitation from $20^{\circ} \mathrm{S}$ above Africa, to the Equator around Indonesia, and back to $10^{\circ} \mathrm{S}$ both west and east of the dateline. The purple dots are not precisely at the location of strongest precipitation. Potential reasons will be discussed in Sect. 4.2. This indicates that excitation of GWs frequently occurs at or in the vicinity of convection, but aloft, that is in the UTLS, and not in the altitudes of strongest updrafts in the troposphere. Gravity waves with lower LTA, i.e., potentially lower source altitudes, have no obvious connection to convection. 


\section{Relation between convection and gravity waves}

In the previous section we have seen for the example of a single day that tropical and subtropical GWs are frequently excited in the UTLS region above convection. In addition, for GWs which can be backtraced to the ground, the raytermination location is remote from any convection. In order to comprehend why this is surprising, we first introduce convection as the main tropical mechanism exciting GWs and briefly review the mechanisms proposed, by which convection may generate GWs (Sect. 4.1). We then (Sect. 4.2) discuss the following questions: is the situation of 29 January 2008 typical? Is it possible to explain all low-latitude GWs by convective excitation? The spectral properties of convectively generated GWs are investigated in Sect. 4.3 and compared to results from other models and from measurements. Finally we ask in Sect. 4.4 why convective GWs in ECMWF data are not realistic.

\subsection{An overview of forcing mechanisms}

Two general concepts of GW excitation by convection are discussed. The first is called the moving mountain model (Pfister et al., 1993), because it is formulated in analogy to orographic GW excitation: at tropopause altitudes frequently a vertical shear of the horizontal wind is observed. It is then assumed that a convective system uplifts the tropopause, causing an obstacle to which the wind reacts by vertical displacement in the same way as for orography on the ground. A real mountain wave has zero phase speed with respect to the ground, but a convective tower moves with the tropospheric wind and evolves and decays, implying a low groundbased phase speed.

The second model assumes resonant forcing due to latent heat release. In its original formulation by Salby and Garcia (1987) two conditions are assumed for most effective forcing of waves: first that a consistent wave pattern is formed throughout the entire troposphere, and, second that the height of the forcing region (almost ground to tropopause in the case of strong convection) equals half the vertical wavelength (or an odd-integer multiple). Based on the dispersion relation in mid frequency approximation $\left(N^{2} \gg \hat{\omega}^{2} \gg f^{2}\right)$,

$\hat{\omega}^{2}=\frac{k^{2} N^{2}}{m^{2}} \Leftrightarrow \hat{c}^{2}=\frac{N^{2}}{m^{2}} \Leftrightarrow \hat{c}^{2}=\frac{N^{2} \lambda_{z}^{2}}{(2 \pi)^{2}}$,

these assumptions govern the horizontal phase speed. For a typical tropopause height and tropospheric buoyancy frequency an intrinsic phase speed of $\sim 30 \mathrm{~m} \mathrm{~s}^{-1}$ is estimated for the maximum of the excited GWMF distribution. Modern formulations (e.g., Beres et al., 2005; Song and Chun, 2008) are more sophisticated. Still, also in modern formulations a consistent forcing throughout the troposphere is most effective in exciting GWs. Accordingly, the phase speed distribution of GWMF takes its maximum in the range of $10-30 \mathrm{~m} \mathrm{~s}^{-1}$, but even much faster waves contribute signif- icantly. Such phase speed distributions match well observations (e.g., Preusse et al., 2001; Ern and Preusse, 2012).

Resonant forcing acts independently of the time scale and horizontal wavelength, which are mainly controlled by the details of the forcing process. Depending on the forcing process horizontal wavelengths range from a few kilometers (Lane et al., 2001; Lane and Sharman, 2006; Jewtoukoff et al., 2013) to several thousand kilometers and periods range from $20 \mathrm{~min}$ to approximately 1 day. Gravity waves of horizontal wavelengths of 20 to $50 \mathrm{~km}$ (e.g., Taylor and Hapgood, 1988; Dewan et al., 1998) due to the the harmonic oscillator effect (Fovell et al., 1992) are too short to be resolved by GCMs. Satellite data observe GWs of a few $100 \mathrm{~km}$ horizontal wavelengths and a few hours period. These are also investigated by mesoscale models and potentially are resolved by GCMs relying on resolved waves only (Hamilton et al., 1999; Watanabe, 2008; Kawatani et al., 2010).

Because a large number of numerical simulations showed wave excitation by resonant forcing, it is generally assumed that resonant forcing by convection is the main source of tropical GW activity. For instance, when Beres et al. (2005) added a parameterization for resonant convective forcing of GWs in their GCM simulations, they assumed that this would provide the main source for tropical GWs and accordingly removed the standard non-orographic scheme at low latitudes. The so-obtained global wind and temperature fields support this approach. But if resonant convective forcing of GWs is the chief source of convective GWs, we expect the backtraces to end in the troposphere. It is therefore surprising that Fig. 3d indicates particularly good spatial collocation for GWs excited above the troposphere in the UTLS. For those regions where Fig. 3d indicates enhanced precipitation there even seems to be a dominance of LTA at tropopause height in Fig. 3c. This also is surprising, if we assume resonant forcing to be the dominant convective excitation mechanism. In addition, we may ask what the sources of low LTA values in regions without convection are.

On the other hand, it is clear that convective GWs in ECMWF data must be validated. The ECMWF parameterization for convection is developed for NWP and therefore designed to produce the correct amount of rain. The fact that the way in which convection is parameterized may heavily influence the spectrum of tropical waves, and in particular GWs, was shown in previous studies (Ricciardulli and Garcia, 2000; Kim et al., 2007). Therefore we are not even sure that GWs excited by convection in the ECMWF model are generated by the same mechanisms as in nature (more details will be given in Sect. 4.4). The convectively coupled largescale waves in ECMWF data are realistic to a large degree (Bechtold et al., 2008; Ern et al., 2008; Jung et al., 2010). The question is open for GWs. ECMWF data are not a controlled experiment in the sense that we can isolate single processes or have control over individual parameters. In addition, we have only access to 6-hourly data and selected parameters. Investigating certain processes in these data is therefore the 
a)

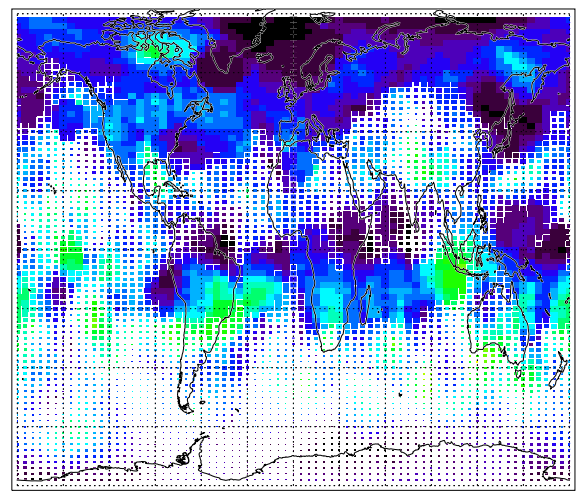

d)

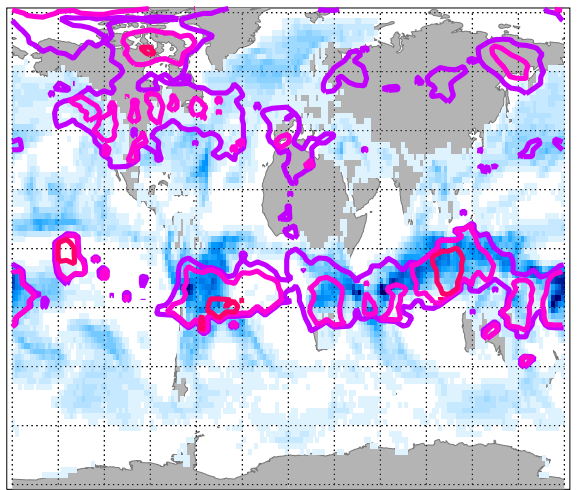

29 Jun 2008 - 05 Jul 2008

b)

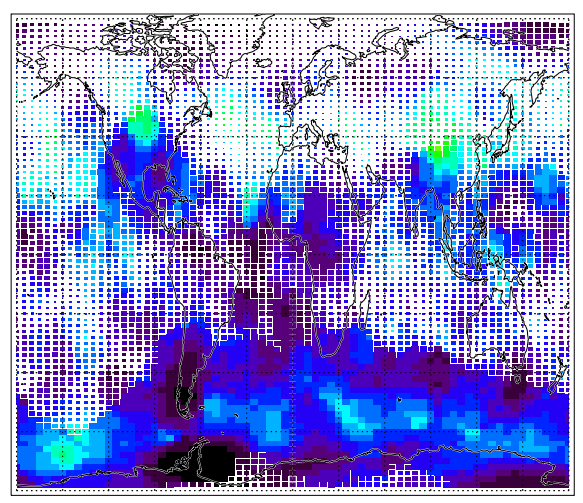

e)

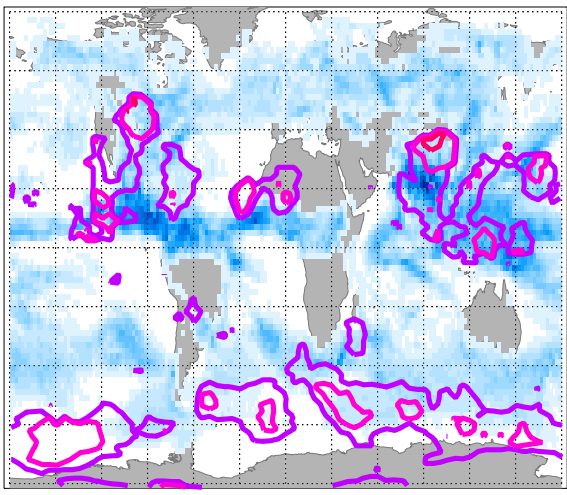

10 Aug 2008 - 16 Aug 2008

c)
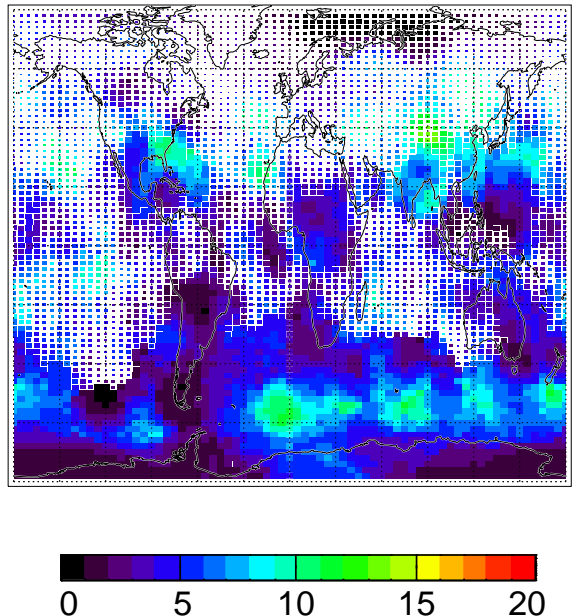

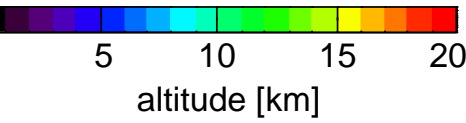

f)
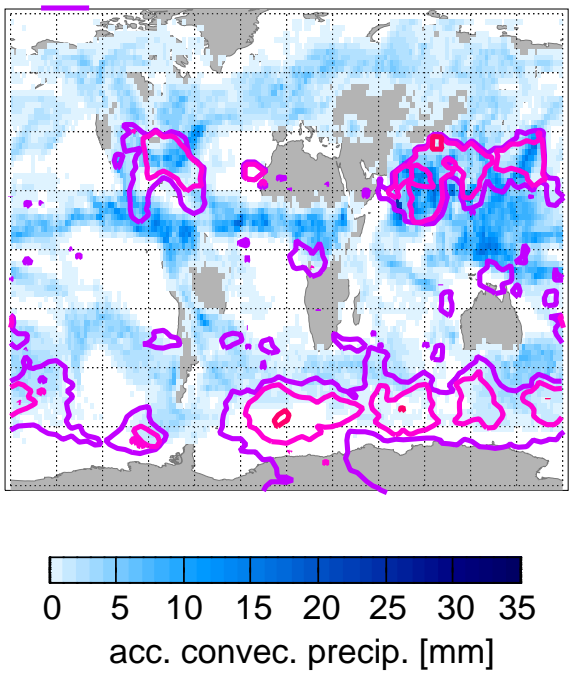

Figure 5. Global maps of (a-c) average LTA (black, $0 \mathrm{~km}$ to red, $20 \mathrm{~km}$ ) and (d-f) accumulated precipitation (transparent, no precipitation to dark blue, $35 \mathrm{~mm} \mathrm{day}^{-1}$ ) for three 1-week periods in January/February (upper row), June/July (middle row) and August 2008 (lower row). Precipitation is smoothed by a box-average of $9 \times 9$ points. For (a), (b) and (a) the length of the rectangles is proportional to the accumulated GWMF for circular source regions of $\pi 800^{2} \mathrm{~km}^{2}$ : the length equals the sampling distance for GWMF of $30 \mathrm{mPa}$ (for details see text). Also shown in the right column by contours are average LTA of $5 \mathrm{~km}$ (purple), $7 \mathrm{~km}$ (pink) and $11 \mathrm{~km}$ (red) only for those regions where accumulated GWMF exceeds $20 \mathrm{mPa}$. 
same kind of puzzle we would have from measurements. The first step is to gain a more statistical view on the problem. We therefore consider the whole 5-week data set of ECMWF data available in this study.

\subsection{Statistical approach to ECMWF data}

In Fig. 3 we have seen particularly high LTA above precipitation. In order to gain a broader data base, we consider the properties of GWs resolved by the ECMWF model for three 1-week periods in Fig. 5. In the left column, color indicates LTA. Values given are 1-week averages in circular bins, each of a $800 \mathrm{~km}$ radius. For the averages, LTA was weighted by the corresponding GWMF at $25 \mathrm{~km}$. The edge length of the rectangles representing the individual bins is proportional to the integrated GWMF in a certain bin; for values of $30 \mathrm{mPa}$ or larger the length is equal to the grid spacing of $2^{\circ}$ latitude and $5^{\circ}$ longitude and the map is completely filled. We have chosen integrated rather than average flux, since this takes also into account the number of rays in a certain bin, i.e., because it better represents the total amount of stratospheric GWMF originating from a given region. On average there are approximately 140 values in every bin, but this number strongly varies with location. The right column shows precipitation accumulated above the same period, i.e., the sum of precipitation during the respective week, again smoothed by a box average of $9 \times 9$ points. In addition, in the right column contours show average LTA of $5 \mathrm{~km}$ (purple), $7 \mathrm{~km}$ (pink) and $11 \mathrm{~km}$ (red). Taken into account are only regions where integrated GWMF is larger than $20 \mathrm{mPa}$. The contour lines hence reproduce from the left column regions where the map is almost completely filled and which have blue or green color.

At low latitudes, the LTA maps (Fig. 5a-c) indicate enhanced values for the summer subtropics, both in LTA value as well as in GWMF. These enhanced values correspond, in a loose way, to regions of large precipitation in the right column. In January, for instance, enhanced precipitation above South America, Africa, the maritime continent and a strong center of convection around the dateline correspond to LTA maxima (indicated by the pink lines on the right column and light blue and green color in the left column), convection west of Middle America, above the southern US (Florida, Gulf of Mexico), the Indian monsoon and, again, Indonesia correspond to LTA maxima in Northern Hemisphere summer. However, the maxima in LTA appear, in general, at somewhat higher latitudes than the precipitation maxima. Enhanced LTA values at the west coast of Africa in panel $c$ have no direct correspondence in precipitation, and there are many rain areas which are not visible in enhanced GWMF with high LTA.

That a correspondence, albeit loose, exists, gives us a hint that in the ECMWF model GWs are excited in the UTLS above or in the vicinity of convection. It does not provide us explanation for the substantial momentum flux of GWs

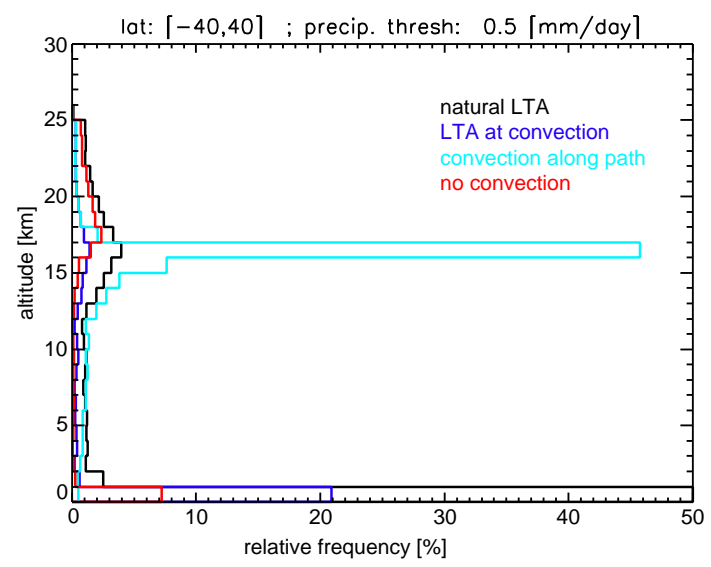

Figure 6. Relative distribution in [\%] of the momentum flux at $25 \mathrm{~km}$ vs. LTA in $[\mathrm{km}]$ for rays terminating between $40^{\circ} \mathrm{S}-40^{\circ} \mathrm{N}$. Data are averaged over all five 1 -week periods. The black line shows LTA as determined by the ray tracer, the dark blue line indicates LTA for only those waves which end over convection. The light blue curve is calculated from rays which were terminated when intersecting precipitation larger than $0.5 \mathrm{~mm} \mathrm{day}^{-1}$. The red line indicates the cases which never pass locations of convection.

for which backtraces end a far distance from any convection. Is this is a different source? Also, if we assume that GWs are excited above convection, why is the correspondence not closer? A tentative explanation for the latter question is connected to oblique propagation of GWs: the source is unlikely to be precisely at the termination position, because the rays are terminated when they reach a critical level where the amplitude vanishes. It is therefore more likely that the true sources of the GWs resolved in the ECMWF data are located somewhere along the ray above the LTA. Since typical raytraces in the tropics have lengths of several thousand kilometers, frequently $10000 \mathrm{~km}$, (not shown), a slightly higher source altitude may correspond to a displacement of several degrees e.g., in latitude. Therefore patterns get blurred or shifted: analyses beyond simple collocation of maps are required for further insight.

In some GCM model studies, convective GW excitation serves as the only source of GWs in the tropics (Beres et al., 2005; Richter et al., 2010). In the following paragraphs we use this as a working hypothesis also for the GWs resolved in the ECMWF data. As discussed above, the true source of a wave is somewhere along its backward trajectory. Following the trajectory backward from the observation, we may assume that the first time this trajectory passes convection is the location of the source. This cannot be visualized properly in maps, so Fig. 6 provides for GWs with ray terminations between latitudes $40^{\circ} \mathrm{S}$ to $40^{\circ} \mathrm{N}$ a statistical view on this problem. Figure 6 shows the relative distribution of GWMF as "observed" at $25 \mathrm{~km}$ altitude dependent on potential source altitude. For all ray traces with LTA in a respective altitude bin, the sum of GWMF normalized to the total GWMF of 
all wave events, i.e., for all altitudes, is shown. The black curve is for all wave events. About $35 \%$ of the momentum flux stems from waves which can be traced down to the ground, but an about equal amount is attributed to altitudes between $13 \mathrm{~km}$ and $18 \mathrm{~km}$, i.e., from the tropopause region. (Note that while $13 \mathrm{~km}$ is a few kilometers below the tropical tropopause, the real source of the GWs is likely above LTA.) If we consider only waves where the ray is terminated close to strong precipitation (dark blue), we see generally fewer waves, but the distribution remains largely unchanged. If we consider only the 1-week period in January (not shown), a relative enhancement in the UTLS is observed. The peak of the blue curve in the UTLS represents GWs which cannot penetrate the UTLS, that means they are excited in this region with very low ground-based phase speed by the ECMWF model. This behavior is expected for the moving mountain model for a convective tower almost at rest.

However, we may assume that the convective tower is variable in time and moves with respect to the wind. Then, according to the original design of the moving mountain model (Pfister et al., 1993), a convective tower excites in the UTLS GWs with ground-based phase speeds larger than the wind velocities at the altitude of strongest wind shear. If such GWs are traced back from an observation at higher altitudes, they pass the true source region, but they can be traced even further downward, since no critical level is encountered. We therefore consider the whole ray path, interpolating both in space and time, and replace the LTA with that altitude (CLTA) where the ray path horizontal location intersects precipitation larger ${ }^{4}$ than $0.5 \mathrm{~mm} \mathrm{day}^{-1}$. The resulting CLTA is shown in the light-blue curve. Almost all waves would now be excited in the UTLS. The total contribution of waves which never have passed convection (shown in red), is very small. Based on the working hypothesis of convection being the dominant source, we can explain almost all waves resolved in ECMWF data by a convection-related source mechanism in the UTLS. This means we reach a consistent picture using this working hypothesis.

To further test the working hypothesis it is assumed that there is a second important source. The consistent picture described above would be reached by mere coincidence in this case: most waves in the tropics travel several thousand kilometers in the horizontal. Therefore it could appear almost unavoidable that at some location they meet convection. We tested this by generating an artificial distribution

\footnotetext{
${ }^{4}$ This threshold is quite low. It was chosen for two reasons. First, this study is based on accumulated rain and can therefore not distinguish between heavy but short precipitation and continuous drizzle. Second, given the horizontal wavelengths of the GWs (cf. Sect. 4.3) and uncertainties in the methods, ray traces in the tropics cannot be expected to match on a $\mathrm{O}(100 \mathrm{~km})$ scale. Each spot of heavy precipitation $\left(>15 \mathrm{~mm} \mathrm{day}^{-1}\right.$ ) in Fig. 3 is surrounded by a larger area of lower values and the lower threshold mimics a widening of the match-radius. Enhancing the threshold leads to a continuous decrease in matches.
}

of precipitation. Both longitude $\psi$ and latitude $\phi$ were inverted $\left(\phi^{*}=-\phi, \psi^{*}=-\psi\right.$; point reflection of the distribution through $0^{\circ}$ lon, $0^{\circ}$ lat). As a result, the peak of CLTA in the UTLS decreased from 46 to $39 \%$ (not shown). This decrease in frequency indicates that the long drawn trajectories very frequently, but not necessarily, meet convection and in turn that the consistent picture of convective GW excitation in the UTLS is an indication, too, that this is the dominant excitation process. Finally, one could imagine that the low threshold generates rather large, continuous areas of precipitation. In this case we hypothetically might identify at tropopause height an intersection of the ray with the convection region at its rim despite the fact that the GW would be really generated at a lower altitude in the center of the convective system. However, the vertical group velocity of these GWs in the ECMWF model is very small and the rays are therefore very oblique. We have tested for this hypothesis and do not find indication for a major contribution of GWs from lower altitudes.

In the UTLS region at altitudes where Fig. 6 indicates many wave sources also the Richardson number minimizes (calculated for this study, but not shown). This indicates that both wind shear and the presence of convection are involved in the excitation of the GWs in the ECMWF model. Are waves with similar properties than those seen in the ECMWF data also observed in nature? Generation of GWs in strong wind shear near the tropopause in monsoon regions was observed by Leena et al. (2010) analyzing GPS radiosonde data from Gadanki, India. From hodographs they analyze the vertical propagation direction and find upward propagation in the stratosphere. In the troposphere, during monsoon season the majority of GWs propagate downward while in all other seasons there are about equal amounts of upward and downward propagating waves. Gravity wave excitation around the tropopause is also reported in earlier studies (e.g., Guest et al., 2000). This indicates that processes like those discussed for the ECMWF model by Fig. 6 also occur in nature. It should, however, be noted that because of the analysis technique the studies of Leena et al. (2010) and Guest et al. (2000) focus on GWs with short vertical wavelengths and with relatively low intrinsic frequencies. The observational evidence is therefore selective and does not represent the full range of GWs occurring in nature.

In summary, all evidence presented in this subsection is pointing to the fact that the majority of tropical GWs in the ECMWF model are excited above the convection but not in the convection. As discussed above, this is also the altitude of strongest wind shear where the Richardson number minimizes. This indicates that both wind shear and convection underneath are required for the forcing of the low-latitude GWs in ECMWF, which have very long horizontal wavelengths and comparably low frequencies. In situ observations provide evidence that such GWs also exist in nature. However, whether they are representative for the low-latitude regions must be decided from global observations. 


\subsection{Spectral properties of convective GWs}

In Sect. 4.2 evidence is presented that low-latitude GWs are excited by convection. There are a number of previous studies of convective GWs which can provide us a reference for the spectral distributions expected for convectively generated GWs. We here focus on two studies. Mesoscale modeling of typhoon Ewiniar ((Kim et al., 2009, 2012)) has been evaluated with a Fourier transform and with the same spectral method (S3D) used here for ECMWF data (Lehmann et al., 2012). By comparing the S3D results of the WRF model study (Lehmann et al., 2012) with S3D results of ECMWF data we use the same method for both data sets excluding methodological biases from the comparison. It should be noted that GWs in Lehmann et al. (2012) are emitted from the rain bands in the spiral arms rather than from the typhoon core. Though the typhoon is still an exceptional event, the spectral distribution should be quite representative also of other areas of deep convection far more frequent than typhoons. For an observational ground truth we use global data from the HIRDLS instrument (Ern and Preusse, 2012) because they provide a statistical average similar to ECMWF data.

The S3D analysis provides for a specific location only the two leading spectral components. However, for a larger region the spectral distribution can be inferred from these individual wave events. By binning the single events according to phase velocity and direction, distributions can be calculated which capture the main spectral features (Lehmann et al., 2012). Since the GW spectrum is filtered by the background winds, we cannot determine the source spectrum from the $\mathrm{GWs}$ at $25 \mathrm{~km}$. However, we can at least determine the part of the spectrum which is relevant for the stratosphere. We focus on the tropics and subtropics and consider latitudes of $40^{\circ} \mathrm{S}-$ $40^{\circ} \mathrm{N}$. In Fig. 7, GWMF at $25 \mathrm{~km}$ is plotted vs. phase velocity and direction at LTA, in the upper row for the January period, in the lower row for a July period, i.e., for southern and northern summer conditions. We here use LTA from the ray tracer without considering the intersection with convection. The left column shows events where backtraces end at the location of convective events, the right column all other cases. In the end we assume that almost all of these waves originate from convection, but the separation allows to consider spectral differences for GWs which are directly related to convection and for the remaining GW events.

Stratospheric low-latitude GWMF peaks in the summer subtropics (cf. Figs. 2 and 5). There we expect mean background winds to be easterly. Accordingly maxima in the spectra in Fig. 7 are found for eastward propagating GWs which in the stratosphere are Doppler shifted to higher intrinsic phase speeds, refracted to larger vertical wavelengths and hence can attain larger amplitudes (Lane et al., 2001; Preusse et al., 2006). In addition, there is a poleward preference, i.e., the prevailing meridional component of the direction is southward in January and northward in August. It
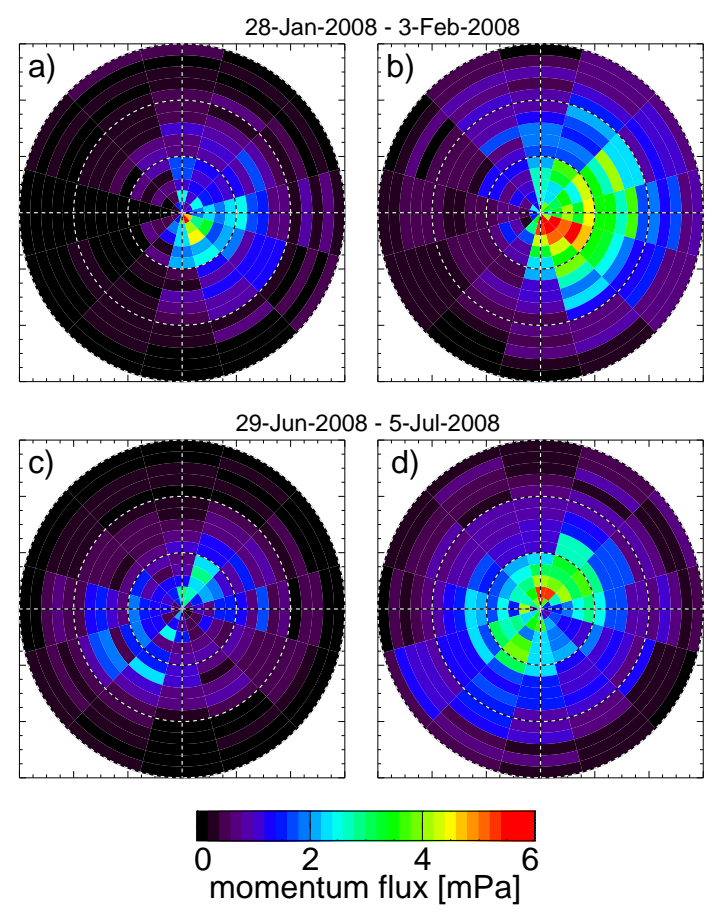

Figure 7. Momentum flux $[\mathrm{mPa}]$ vs. phase speed (distance from center, $\left[\mathrm{ms}^{-1}\right]$ ) and azimuthal direction (eastward, positive $x$; northward, positive $y$ ). The left column (a, c) shows cases for which backtraces naturally end at convection, i.e., intersection of rays with convection is not taken into account. The right column (b, d) shows all other cases. The upper row $(\mathbf{a}, \mathbf{b})$ gives spectra for the period 28 January 2008 to 3 February 2008, the lower row (c, d) gives spectra for the period 29 June 2008 to 5 July 2008. Black and white dashed concentric circles indicate 20,40 and $60 \mathrm{~m} \mathrm{~s}^{-1}$ phase speed.

should be kept in mind that this is the shape of the spectrum as observed after filtering by the background atmosphere and hence we cannot distinguish whether this poleward preference is already present in the source spectrum or whether it is a result of the propagation from the source to the observation altitude. The general preference of poleward propagation is also visible in observations: Jiang et al. (2004b) find in Microwave Limb Sounder (MLS) observations a poleward shift with altitude of the convective maxima and also Ern et al. $(2011,2013)$ find in zonal mean HIRDLS and SABER distributions that the subtropical maximum is tilted poleward with altitude.

In Fig. 7, phase speeds are higher for the right column. This is not trivial to discern, since integrated GWMF is generally higher in the right column. However, while peak values at low phase speeds in panels a and $\mathrm{b}$ are $6 \mathrm{mPa}$ and values around $10 \mathrm{~m} \mathrm{~s}^{-1}$ phase speed are about $4-5 \mathrm{mPa}$ in both panels, there is a distinct arc of almost $5 \mathrm{mPa}$ in panel $\mathrm{b}$ for phase speeds of $\sim 20 \mathrm{~m} \mathrm{~s}^{-1}$, whereas values in panel a are about $2 \mathrm{mPa}$. This supports the interpretation in Sect. 4.2 that a large number of GWs are excited above convection with non-zero ground-based phase speeds and that for these 
waves the backtraces pass but do not end at convection. These events are forming the majority of the events in the right column. However, both in the left and the right column the ground-based phase speeds of the waves are low, peaking below $10 \mathrm{~m} \mathrm{~s}^{-1}$ and most of the GWMF is found below $20 \mathrm{~m} \mathrm{~s}^{-1}$. This differs from e.g., the typhoon simulations of Kim et al. (2009) using the WRF model (Skamarock et al., 2005). These data were analyzed by Lehmann et al. (2012) with the same technique as used here. Phase speed distributions of GWMF in the typhoon case peak around $20 \mathrm{~m} \mathrm{~s}^{-1}$ and extend to higher phase speeds.

Unfortunately there are very few measurement techniques which can deduce the direction of GWs and hence there are no global statistics of the ground-based phase speed. However, horizontal wavelengths were estimated from HIRDLS data for convective source regions in the subtropics (Ern and Preusse, 2012). In Fig. 8 the HIRDLS spectra for convective regions (left column) are compared with spectra from ECMWF data (right column). For better orientation, gray coordinate lines indicate $10 \mathrm{~km}$ vertical wavelength and $1000 \mathrm{~km}$ horizontal wavelength, respectively. For the satellite data, only the wavelength along the satellite track can be deduced and due to sampling issues there will be also a certain amount of aliasing (Ern et al., 2004). In addition, the visibility filter of infrared limb sounders decreases at short horizontal wavelength (Preusse et al., 2002). In order to illustrate these points quantitatively, we apply an observational filter mimicking the HIRDLS observations to the ECMWF data shown in Fig. 8e and present the results in Appendix B. Because of these effects the spectra from HIRDLS are expected to underestimate GWMF, in particular at short horizontal wavelength and indicate too large GWMF for larger horizontal wavelengths, i.e., the spectrum will be somewhat shifted toward lower horizontal wave numbers. In contrast, for ECMWF data the true horizontal wavelength of the resolved waves is estimated. However, in the left column the peak for observed GWMF is at horizontal wavelength of a few $100 \mathrm{~km}$ and the contribution of GWs longer than $1000 \mathrm{~km}$ is small. In contrast, the opposite is the case for ECMWF data: GWs resolved by the ECMWF model peak at more than $1000 \mathrm{~km}$ horizontal wavelength and the contribution of wavelengths shorter than $1000 \mathrm{~km}$ is small. Thus, tropical GWs in ECMWF data have a substantial high bias in their horizontal scales of at least a factor of 3 compared to observations, potentially more.

It should be noted that very long horizontal wavelengths have been observed by satellite observations (Preusse, 2001) and radiosondes (Leena et al., 2010). Gravity waves of these scales exist in nature. However, the first example is a case study and the latter uses a selective technique. It is therefore the shift of the GWMF spectrum towards longer horizontal wavelengths in a climatological average which makes the ECMWF data non-realistic.

The spectra from HIRDLS are limited to vertical wavelengths shorter than $25 \mathrm{~km}$ (Ern and Preusse, 2012). For
HIRDLS

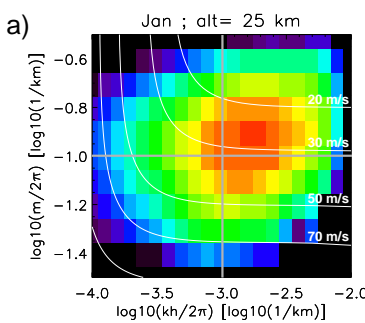

b)

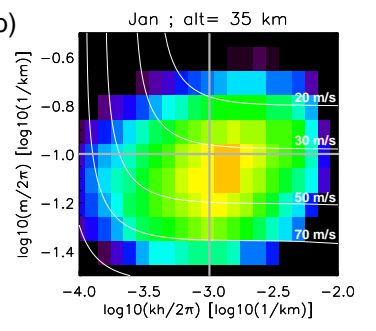

c)

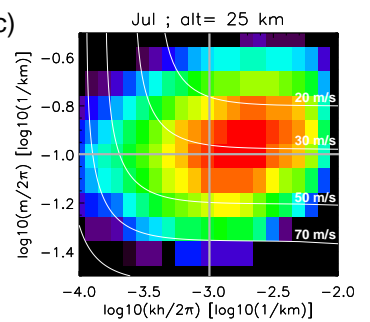

d)

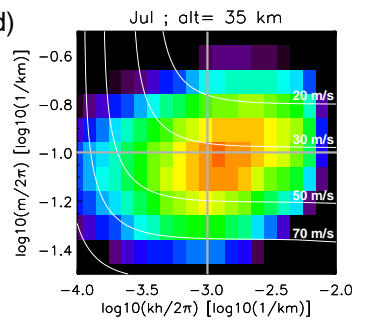

ECMWF
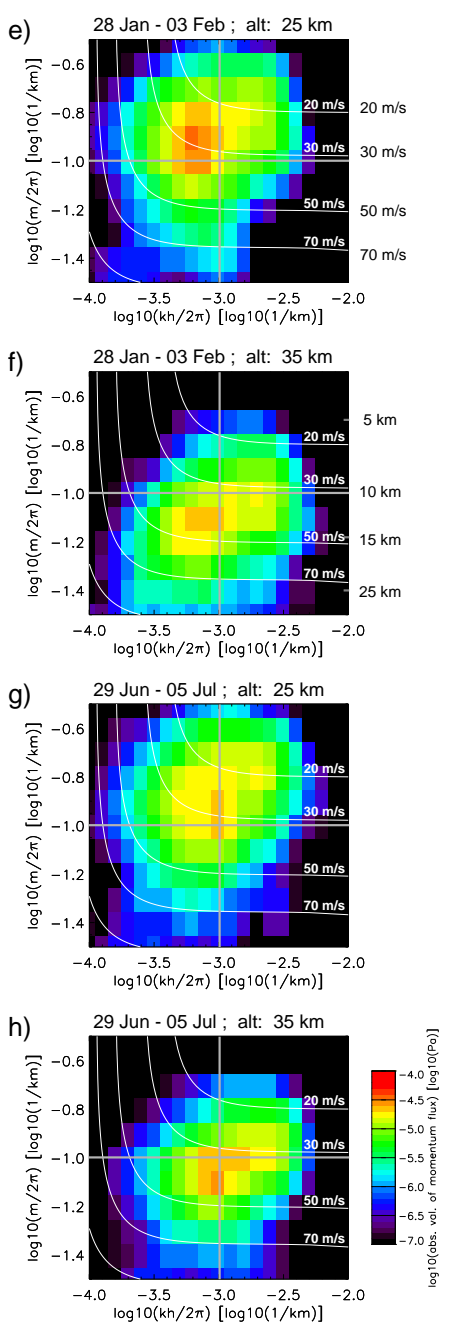

Figure 8. Spectra of GWMF normalized to the total number of all wave events ([log10 over $1 \mathrm{~Pa}]$; black, $10^{-4} \mathrm{mPa}$ to red, $0.1 \mathrm{mPa}$ ) vs. horizontal and vertical wave number (both $\left[\log 10\right.$ of $\left.\mathrm{km}^{-1}\right]$ ). Due to observational effects, spectra from HIRDLS (left column) are long-biased compared to the true distributions in terms of horizontal wavelength, but still peak at much shorter horizontal wavelengths than spectra from ECMWF (right column). For better orientation, the gray grid-lines indicate $10 \mathrm{~km}$ vertical wavelength and $1000 \mathrm{~km}$ horizontal wavelength, respectively. White lines give intrinsic phase speed (labels are reproduced at the right $y$ axis of (e)). Vertical wavelength values are given at the right $y$ axis of (f).

ECMWF data a $50 \mathrm{~km}$ vertical wavelength limit is used. Therefore spectra generated from ECMWF data potentially could show longer wavelengths than the measurements. Again, the opposite is the case: spectra from ECMWF data are peaking at somewhat shorter vertical wavelengths and are weaker for the long vertical wavelength part. This points to too low phase speeds, the same effect as also discussed for the phase speed spectra in Fig. 7 compared to the typhoon simulations. For $25 \mathrm{~km}$ altitude and very short vertical 
wavelengths, ECMWF data indicate larger GWMF than HIRDLS observations, which is likely due to a decreased sensitivity of HIRDLS for GWs with wavelengths shorter than 4-5 km and should not be physically interpreted.

There is one feature shedding light on the propagation of GWs, which is well reproduced by ECMWF data, though. Spectra at $25 \mathrm{~km}$ altitude (first and third row) peak at much shorter vertical wavelengths than spectra at $35 \mathrm{~km}$ altitude (second and fourth row). This shift towards longer vertical wavelengths is likely due to larger background wind velocities as well as to a general shift towards longer vertical wavelengths because of amplitude growth and saturation (e.g., Gardner et al., 1993; Warner and McIntyre, 1999; Preusse et al., 2009a; Ern et al., 2011).

\subsection{Why are ECMWF convective GWs not realistic?}

Given the known sensitivity of modeled stratospheric GWs on the convective parameterization (Ricciardulli and Garcia, 2000; Kim et al., 2007) and given that the parameterization in ECMWF is particularly optimized to produce the correct amount of rain, we discuss the ECMWF convective parameterization in this section. This parameterization contains both updraft and downdraft in a single ECMWF grid cell (Persson and Grazzini, 2005). Only the residual motions are coupled to the model dynamics. Accordingly convection is not fully coupled to the dynamics of the GCM and hence GWs by resonant forcing are not present. This can be beneficial also for data assimilation since potential misrepresentation in the details of convection do not disturb assimilation of other quantities.

An example for this missing coupling between the convective parameterization and the dynamical core is presented in Fig. 9, which shows high resolution vertical winds at $10 \mathrm{~km}$ altitude for 28 January 2008, i.e., $36 \mathrm{~h}$ prior to the stratospheric GWs discussed in Figs. 2 and 3. There are some features above orography at mid and high northern latitudes which are likely connected to orographic GWs. Examples are central Europe, Norway, Spitsbergen and the Rocky Mountains. There are also some structures along the convective tropical rain bands. However, these are of the order of $0.2 \mathrm{~m} \mathrm{~s}^{-1}$ or smaller. In convective updrafts vertical winds can be as strong as several $10 \mathrm{~m} \mathrm{~s}^{-1}$ and velocities exceeding $10 \mathrm{~m} \mathrm{~s}^{-1}$ are frequent (e.g., Wu et al., 2009; Collis et al., 2013). However, the modeled vertical velocity strongly depends on the use of the microphysics and boundary layer schemes as well as on the spatial resolution of the model (an adequate horizontal grid-spacing would be less than $1 \mathrm{~km}$, e.g., Wu et al., 2009; Del Genio et al., 2012). Still, typhoon simulations performed for investigation of the emission of stratospheric GWs with a resolution of $25 \mathrm{~km}$ (e.g., Kim et al., 2009, 2012) show updrafts of several $\mathrm{m} \mathrm{s}^{-1}$. Compared to these values, vertical winds in the ECMWF model which runs at a similar resolution as the typhoon simulations are tiny.

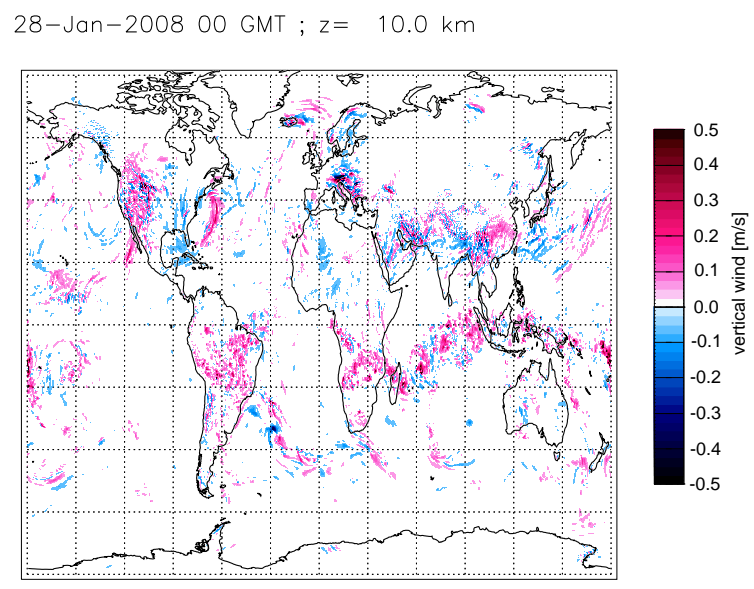

Figure 9. Vertical winds for 28 January 2008, $10 \mathrm{~km}$ altitude; dark blue indicates values of $-0.5 \mathrm{~m} \mathrm{~s}^{-1}$ or less, dark red indicates values of $0.5 \mathrm{~m} \mathrm{~s}^{-1}$ or more.

This missing coupling to the dynamical core of the GCM and the tiny wind speeds are the likely reason that GWs in the ECMWF model are excited aloft of convection in the shear region in the UTLS rather than by resonant forcing in the troposphere. This in turn causes ECMWF-resolved GWs to have overly slow phase speeds and overly long horizontal wavelengths. More realistic GWs may enhance the skills of a NWP system for seasonal prediction. One promising pathway to seasonal prediction is the QBO (Scaife et al., 2014). Capturing the seasonal cycle of tropical GWs (Krebsbach and Preusse, 2007) may enhance the models capability to predict the QBO and, via teleconnections, surface temperatures in Northern Hemisphere winter (Scaife et al., 2014). However, the primary focus of NWP systems is on shortterm forecasts. If a different scheme for convection would adversely affect precipitation prediction or assimilation skills, it would unlikely be applied. It is therefore important that both weather-forecast and middle atmosphere aspects are investigated in detail and simultaneously, if NWP models shall be employed for seamless climate prediction.

\section{Gravity waves at higher latitudes}

In Sect. 3 strong GW excitation by orography and a storm are described and in the previous section we focus on GWs at low latitudes. However, observations indicate largest GWMF in the southern winter polar vortex, remote of any orography. This high GWMF is persistent and not connected with unusual weather events. What are the sources of ECMWFresolved GWs in this region?

Figure 5 also shows sources of high latitude GWMF in the polar vortices. Several features are observed. First, the Antarctic Peninsula and the southern part of South America are very clearly identified as prominent GW sources. At these regions LTA is close to zero indicating that orography is the 
cause of GWs. Enhanced GWMF in these regions excited by orography is in very good agreement to observations and process modeling (e.g., Fetzer and Gille, 1994; Eckermann and Preusse, 1999; Jiang et al., 2002; Alexander and Barnet, 2007; Alexander et al., 2008; Hertzog et al., 2008; Ern et al., 2011; Plougonven et al., 2013). Second, apart from these orographic sources, there is a general band of wave origins for high GWMF for almost all longitudes $\left(60^{\circ} \mathrm{W}\right.$ to $\left.180^{\circ} \mathrm{E}\right)$. These wave origins are not matching topography and hence indicate some other sources.

The source of high GW variance at polar latitudes is under debate since first seen in space observations (Fetzer and Gille, 1994; Wu and Waters, 1997; Preusse et al., 1999). Recently, high momentum flux required for the momentum balance in GCM was attributed for instance to fronts (Charron and Manzini, 2002; Richter et al., 2010), convection (Choi and Chun, 2013) and small islands (Hoffmann et al., 2013). A recent study of Hendricks et al. (2014) attributes the belt of large stratospheric GWMF to instabilities at $500 \mathrm{hPa}$, where in the storm tracks large eddy growth rates are found. Gravity waves found in our study, which originate between 30 and $50^{\circ} \mathrm{S}$ and have LTA in the troposphere, likely are generated in the storm tracks and support the hypothesis of Hendricks et al. (2014). For instance, Fig. 5c indicates large GWMF of tropospheric LTA around Cape Town. However, between 50 and $60^{\circ} \mathrm{S}$ average LTA are higher than $7 \mathrm{~km}$, in some regions higher than $12 \mathrm{~km}$ on average. As the source level is always higher than LTA, the LTA values indicate sources in the stratosphere. Also, since the wave origins are between 50 and $60^{\circ} \mathrm{S}$, the sources seem not to be connected with the tropospheric storm tracks, which are located equatorward. In summary, indication is found for GWs from the storm tracks propagating obliquely and being focused into the stratospheric jet. However, in addition, a further source at the lower edge of the stratospheric jet is required to explain the GWMF values observed in the edge of the polar vortex in ECMWF data. A large part of the GWMF in the southern polar vortex is therefore likely caused by some kind of jet instability or spontaneous adjustment in the lower stratosphere.

A puzzling feature in stratospheric climatologies of GWs is the low GWMF over the Rocky Mountains (Geller et al., 2013) compared to GWMF over several other much smaller and lower mountainous regions. In Fig. 9 high activity is seen in the troposphere above the Rocky Mountains which, however, does not reach the stratosphere. For instance, Fig. 5 indicates no orographic waves from the Rocky Mountains for the period 28 January to 3 February 2008. This is in agreement with observations (Jiang et al., 2004a; Geller et al., 2013) which show very low GW activity above the Rocky Mountains. This was reproduced for the MLS climatology by ray tracing calculations with the Naval Research Laboratory (NRL) mountain wave forecast model (Jiang et al., 2004a) and is likely due to the position of the stratospheric jet in the Northern Hemisphere. In the episode investigated in this paper the ECMWF model reproduces the filtering of moun- tain waves from the Rocky Mountains preventing them from entering the stratosphere.

\section{Temporal variability}

The spatial distribution of global GW momentum flux is dominated by subtropical GWs from convection in the summer hemisphere and by GWs from orography, storms and spontaneous imbalance in the winter hemisphere. Both form distinct maxima, one at subtropical latitudes of the summer hemisphere and the other at mid and high latitudes of the winter hemisphere (cf. Figs. 2 and 5 for ECMWF data and Ern et al. (2011) for observations). In both cases the prevailing propagation direction is opposite to the prevailing background winds, i.e., the waves propagate mainly eastward in summer and westward in winter. In order to capture the temporal variation we present total hemispheric GWMF in Fig. 10. In integrating over an entire hemisphere we capture either the summertime subtropical maximum or the wintertime high-latitude maximum, depending on hemisphere and season, but avoid an influence of the integration area that could be induced by latitude limits focused on specific regions or latitude bands. We calculate zonal mean net GWMF directly from the full model data by

$F_{x, \mathrm{mf}}=\bar{\rho} \overline{u^{\prime} w^{\prime}}$,

where the overbar indicates the zonal average. We then integrate this zonal mean net flux over latitudes $0^{\circ}$ to $90^{\circ} \mathrm{N}$ for the Northern Hemisphere shown in Fig. 10a and $0^{\circ}$ to $90^{\circ} \mathrm{S}$ for the Southern Hemisphere shown in Fig. 10b. Different altitudes of $25 \mathrm{~km}$ (black), $35 \mathrm{~km}$ (green) and $45 \mathrm{~km}$ (red) are indicated by color. Different periods are separated by the vertical green lines. The first period in the left panel is for northern winter and is dominated by westward flux, the second period in April is the quiet season for GWs on both hemispheres, periods 3 and 4 are typical summer-time conditions with subtropical eastward flux, and in period 5 in early fall the end of the convective season results in reduced subtropical waves. Analogously we find for the Southern Hemisphere in the right panel summer conditions, the quiet season in April and different stages of winter conditions throughout periods 3 to 5 . All this general behavior is also found in various climatologies from observations and dedicated modeling (e.g., Wu and Waters, 1997; Fröhlich et al., 2007; Preusse et al., 2009a; Ern et al., 2011).

A remarkable feature is a jump of a factor of 3 in average hemispheric GWMF from 28 to 29 January, i.e., from one day to the next inside period 1 . This is due to the two major events of orographic GWs at Greenland and the storm east of Norway discussed in depth in Sect. 3. Similarly, in the Southern Hemisphere, day-to-day variations of a factor 2 are observed in winter. In contrast, GWMF in the summer hemisphere is almost steady. On a first instance those facts may seem surprising in that convection, which is very 

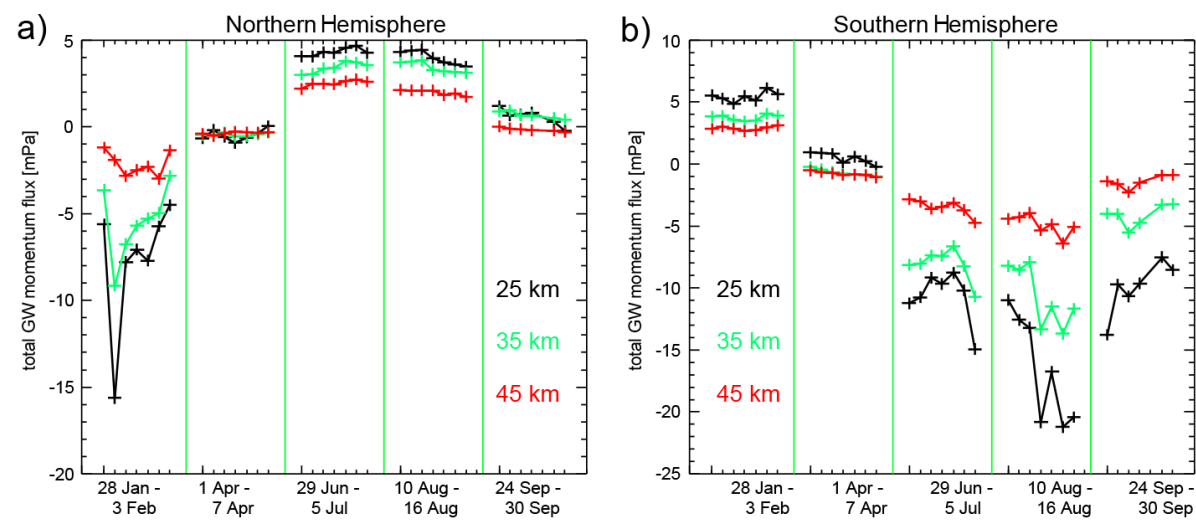

Figure 10. Zonal gravity wave momentum flux calculated according to Eq. (5) from the full-resolution model winds and integrated over latitudes $0^{\circ}$ to $90^{\circ} \mathrm{N}$ for the Northern Hemisphere is shown in (a) and integrated over latitudes $0^{\circ}$ to $90^{\circ} \mathrm{S}$ for the Southern Hemisphere is shown in (b). Color indicates altitudes of $25 \mathrm{~km}$ (black), $35 \mathrm{~km}$ (green) and $45 \mathrm{~km}$ (red). The individual 7-day periods are separated by vertical green lines.

intermittent, causes a steady flux, while orography, which in itself does not alter, excites GWs with huge variations in GWMF. However, considering a sufficiently large area, tropical and subtropical convection will form and decay every day, though at different positions but for a larger area in a very persistent manner over the whole rain season. Also the general fact that mountain waves are highly dependent on the specific wind profile throughout the troposphere is well known and has been reported for instance for the southern Andes (Eckermann and Preusse, 1999; Jiang et al., 2002). The much larger variability in regions dominated by orographic GW excitation has been also quantified statistically in terms of an intermittency factor, both from satellite and superpressure balloon measurements (Hertzog et al., 2008, 2012) as well as from quasi-hemispheric mesoscale modeling (Plougonven et al., 2013).

The accuracy and data density of current-day satellites or superpressure balloons is insufficient to calculate meaningful daily averages. In order to infer the impact of single events on the variability of GWMF in a wider region we therefore have to rely on model data. Plougonven et al. (2013) show that the Antarctic Peninsula dominates the variability of GWMF in the latitude range 90 to $50^{\circ} \mathrm{S}$ and can cause day-to-day variations of a factor of 2 or more. Our study shows that the variability in the Northern Hemisphere may be even higher and we find bursts in the total hemispheric flux by a factor of 3. It should be noted that such bursts of GWMF may be even underestimated in ECMWF or WRF data due to the fact that short horizontal wavelength GWs are missing.

\section{Summary}

ECMWF data are analyzed for GWs at $25 \mathrm{~km}$ altitude and the resulting waves are backtraced to potential sources, that is, the true source can be located at any altitude above the ter- mination altitude of the ray. By this analysis we infer properties and sources of GWs resolved by the ECMWF model. Where ECMWF-resolved GWs are realistic, this also provides valuable insight for GWs in nature.

In global distributions of the termination location orographic sources such as Greenland, the Antarctic Peninsula and South America as well as a storm approaching the Norwegian coast are identified. In these regions GWs propagate in less than 1 day to $25 \mathrm{~km}$ altitude. Elsewhere GWs on average need more than 2 days from source to $25 \mathrm{~km}$ altitude. Mountain waves and GWs from storms cause bursts in the total hemispheric fluxes by factors of 2 (Southern Hemisphere) or 3 (Northern Hemisphere).

Using spatial correlation, we would have misinterpreted the strong GWs at northern Norway to be mountain waves, i.e., we would have overestimated the influence of mountain waves on the global flux considerably. Backtracing is a very well suited tool to avoid such misinterpretations. It can be applied to GW resolving models and observations which fully characterize the waves, such as super pressure balloons (Hertzog et al., 2008), but not to current-day satellite observations.

Resolved GWs in ECMWF data have at low latitudes very long horizontal wavelengths of more than $1000 \mathrm{~km}$, much longer than the typical wavelengths indicated by observations for these regions. Tropical phase speed spectra generated from ECMWF data peak at less than $10 \mathrm{~m} \mathrm{~s}^{-1}$, slower than expected from mesoscale modeling and also from observations. Global maps indicate that the location of the source is related to convection. Furthermore, when using backtracing, we find that almost all rays pass somewhere above a convective system in the UTLS. This gives evidence that the likely source is related to convection. The tropical GWs in ECMWF are generated in the region of highest shear aloft the convective system. Such waves have been observed in case studies from observations. However, comparison to 
other modeling studies and satellite data shows that they are not representative of the tropics. Instead, resonant forcing is assumed to be the most important process in generating convective GWs and is the basis of recently developed GW source parameterizations for GCMs. Therefore this result is rather unexpected. Also horizontal wavelengths of convective GWs in ECMWF data are much longer than in observations. This is not a problem of the model resolution: it should be noted that the spatial resolution of the ECMWF model would be sufficient to resolve GWs of scales as observed by the satellites. Also several studies of typhoon-generated GWs were performed at similar spatial resolution as these ECMWF runs and generate distributions peaking at a few hundred kilometer horizontal wavelengths.

Several previous studies, however, indicated that the parameterization for convection may be crucial in determining the spectrum of waves excited. The convective parameterization in ECMWF comprises the dynamics of a convective system inside a single grid cell, i.e., it comprises both updrafts and downdrafts and couples only the residual effects to the dynamical core of the GCM. These residual effects are much weaker than the dynamics of a resolved convective system and the GCM therefore cannot correctly represent the tropical GWs.

Almost all results obtained in this paper are based on simulated satellite observations from an infrared limb imager. For current-day instruments we can only diagnose sources by either spatial collocation, which can be highly misleading as shown above, or by forward modeling and comparison, which leaves many uncertainties about the details of the model used. However, as demonstrated in the paper, full wave characterization by an infrared limb imager would allow us to determine source regions and source processes much more accurately by backward ray tracing. In addition, much more stringent constraints on the phase speed and wavelength distribution (cf. discussion of Figs. 7 and 8) would be possible. The paper therefore is also a demonstration of the huge potential of an infrared limb imager for GW research.

High resolution global weather forecast data contain GWs from many processes. By means of data assimilation they capture well the synoptic scale meteorology. If the processes generating GWs from different sources are well represented in the GCM, they are a suitable tool also for predicting GW activity. (Please note that data assimilation so far has not been proven to improve the representation of the GW structures in a model: the GWs need to be generated by the model from the synoptic scale structures self consistently without further guidance from data.) Despite the fact that there will be some differences due to missing resolution also at high latitudes, main distributions and general features at mid and high latitudes are broadly realistic. Further validation, however is required. ECMWF data may then at higher latitudes be very helpful to explore the nature of GW source processes.
Ever since satellites observed extremely high GWMF in the Antarctic winter polar vortex far from orography, the source of these waves is puzzling. For instance, Hendricks et al. (2014) attribute these GWs to excitation by instability growth in the troposphere, but do not identify the actual source altitude of the waves seen in the stratosphere. In the current study, we find indication for such waves from the storm tracks. In addition, backward ray tracing gives evidence that many GWs in the Antarctic winter polar vortex originate from jet instabilities around the tropopause or in the lower stratosphere.

A further potential use of ECMWF data is identifying regions and periods of enhanced GW activity in order to guide measurement campaigns for investigating generation, propagation and dissipation of GWs. Finally, a validated global model can also help to understand e.g., day-to-day variations in a regional or global context, which cannot be captured by today's measurements. In contrast, GWs from convection cannot be considered as realistic.

This brings us back to our original question in the introduction: will increasing resolution in seamless climate modeling automatically result in a good representation of GWs? In other words, will it make dedicated GW research and parameterizations obsolete? The examples presented in this paper give evidence that at least validation is further required. Parameterizations optimized for a certain end, here the prediction of precipitation, may fail to capture or generate other aspects. Thus a sound understanding of all processes would be a prerequisite to seamless climate prediction. Therefore, another prerequisite is that the model development is driven also by processes related to climate projection. This means slightly changing the philosophy, since historically the development of NWP models is dominated by effects, e.g., relevant for the short-term weather forecast skills.

In case of the tropical convection, the model does not only underestimate the short horizontal wavelength part of the GWMF spectrum, but it also overestimates the long horizontal wavelength part of the GWMF spectrum. Where GWMF is underestimated, a parameterization may be employed to represent these waves in a GCM. However, where GWMF is too large in respect to reality, there is no concept for removing this excessive GWMF. The scales of the waves conveying the GWMF for lower to higher altitudes matter: waves of different wavelengths have different propagation properties and will influence higher altitudes in the atmosphere differently. Thus, a shift in wavelengths, which could be present also for other sources such as spontaneous imbalance, may alter the behavior of the middle atmosphere e.g., in a climate run. Such spectral shifts and even overestimation of GWMF can be produced even at very high resolution (Lane and Knievel, 2005), in fact even at resolutions which are orders of magnitude higher than for the current ECMWF model. 


\section{Appendix A: Correlation between GWMF from temperatures and winds}

In order to test the accuracy and precision of our results as well as to test whether the investigated mesoscale structures are really GWs, we compare GWMF determined from temperatures with GWMF from winds. GWMF for temperatures is calculated according to equation 1 for the two mostimportant wave components in each fitting cube. These two wave components are added for total zonal and meridional GWMF in each individual fitting cube. For the winds we calculate residuals of all three wind components $\left(u^{\prime}, v^{\prime}, w^{\prime}\right)$ by removing zonal wave numbers $0-6$ and interpolate these wind residuals to the measurement grid, same as for temperatures. The wave vectors of the two most important wave components for the vertical wind residuals $w^{\prime}$ are fitted in the same fit-volumes as used for temperature. Based on these wave vectors, amplitudes for all three wind components are determined by sinusoidal fit. Then for each wave component GWMF is determined from the wind amplitudes $(\hat{u}, \hat{v}, \hat{w})$ by

$\left(F_{x}, F_{y}\right)=\frac{1}{2} \rho(\hat{u} \hat{w}, \hat{v} \hat{w})$

Note that Eq. (A1) does not rely on the polarization and dispersion relations of GWs and does therefore not require wave parameters such as the wave vector. However, this comes at the prize that Eq. (A1) is not the exact formulation for GWs but the mid-frequency approximation. Therefore GWMF is overestimated for low frequency waves and GWMF from temperatures is modified accordingly for this comparison. Again total zonal and meridional GWMF in each fitting cube are calculated by adding the two most important wave components.

Figure A1 shows the point density function of the correlation of individual fitting cubes at $25 \mathrm{~km}$ altitude for 34 days, starting from 29 January, in total approximately 100000 values. Note that the color scale is logarithmic, i.e., orange represents 10000 fitting cubes in one bin (bin size is $0.5 \mathrm{mPa}$ ). The left panel shows zonal GWMF, the right panel meridional GWMF. On the $x$ axis the values determined from winds, on the $y$ axis the values determined from temperatures are provided. The white lines show, (solid) the linear regression, (dashed) the width in the center of the distribution and, (dashed dotted) the relative width of the distribution. The absolute width is determined by generating from the individual cubes a histogram with respect to the absolute distance from the regression line for the central part of the distribution. The relative width is estimated by generating a histogram with respect to the relative distance from the regression line for the part with larger GWMF.

The statistical measures for the two comparisons are provided in Table A1. In particular zonal GWMF correlates very well between temperatures and winds. There is a general low bias of ECMWF temperature-based GWMF with respect to wind-based GWMF which is not observed in other model
Table A1. Statistical measures from the correlation analysis between GWMF from temperatures and winds for the zonal and meridional component. More than 100000 values were used for each of the statistical analyses.

\begin{tabular}{lcc}
\hline Measure & $\begin{array}{c}\text { Zonal } \\
\text { GWMF }\end{array}$ & $\begin{array}{c}\text { Meridional } \\
\text { GWMF }\end{array}$ \\
\hline correlation coefficient R & 0.97 & 0.88 \\
slope of linear regression & 0.81 & 0.68 \\
absolute width at center [mPa] & 0.12 & 0.15 \\
relative width [\%] & 16 & 21 \\
\hline
\end{tabular}

data (Lehmann et al., 2012) and is also not caused by the midfrequency approximation (tested, not shown). This seems to be a peculiarity of the ECMWF model.

The slope determined by the linear regression varies with season (not shown). By calculating a common linear regression for all seasons the variation of the slope causes a wider relative deviation. Therefore the relative width is slightly larger than the single-day values referred to in Sect. 2 of this paper.

The fact of the very good correspondence between temperature-based and wind-based GWMF shows that the majority of the investigated mesoscale structures obey the polarization and dispersion relations of GWs. This is evidence that at least the majority of the investigated mesoscale structures are GWs.

\section{Appendix B: Observational filter}

In this appendix we show for the example of the spectra presented in Fig. 8e how the observational filter of an infrared limb sounder modifies and shifts the spectral shape. These shifts are notable, but do not affect the main findings presented in Sect. 4.3.

A detailed discussion of a comprehensive observational filter for infrared limb sounders will be given in a dedicated paper (Trinh et al., manuscript in preparation for AMT) and we here give only a brief outline. The main effects of the observation and the analysis method for GW momentum flux estimates from infrared limb sounders are described by Ern et al. (2004) and Preusse et al. (2009b). (Please consider in particular Fig. 3 in Preusse et al., 2009b.) The observational filter takes the following into account: the visibility filter in the direction of the line-of-sight due to radiative transfer and retrieval in linear approximation (cf. Preusse et al., 2002), some filtering mimicking the vertical-profile spectral analysis, the projection of the horizontal wavelength on the tangent point track and, finally, aliasing. For simulation of these effects, we need to determine the apparent wavelength of the wave along the horizontal projection of the line of sight of the satellite instrument, as well as the apparent wavelength of the wave projected onto the track of tangent-points. The 

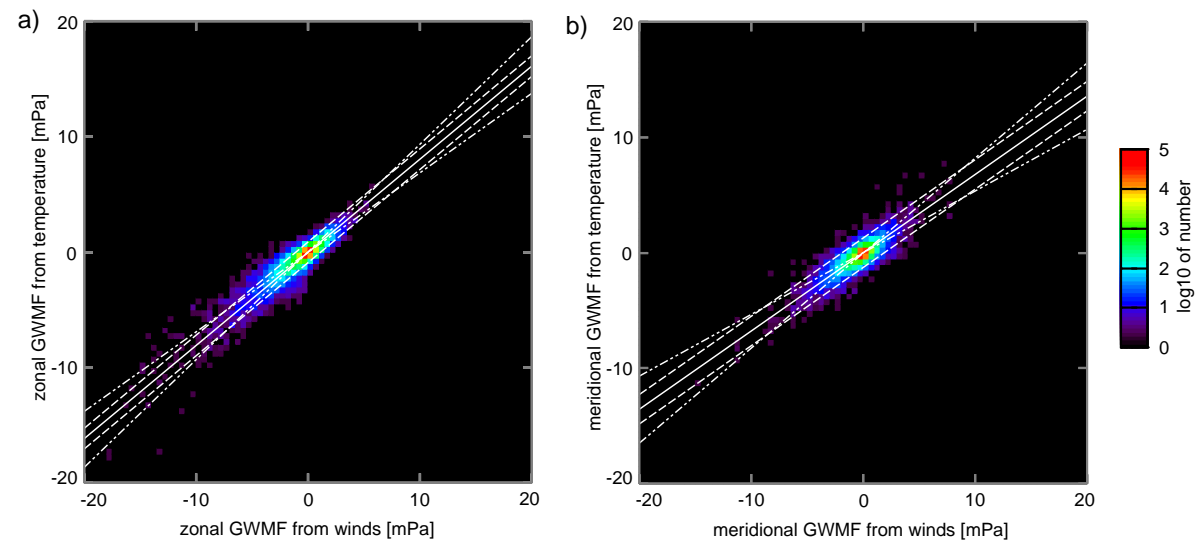

Figure A1. Logarithmic point density of (a) zonal and (b) meridional GWMF inside all fitting-cubes at $25 \mathrm{~km}$ altitude. On the $x$ axis the value determined from winds, on the $y$ axis the values determined from temperatures are provided. The white lines show (solid) the linear regression (dashed) the width in the center of the distribution and (dashed dotted) the relative width of the distribution. Black color indicates no wave events in the respective bin.
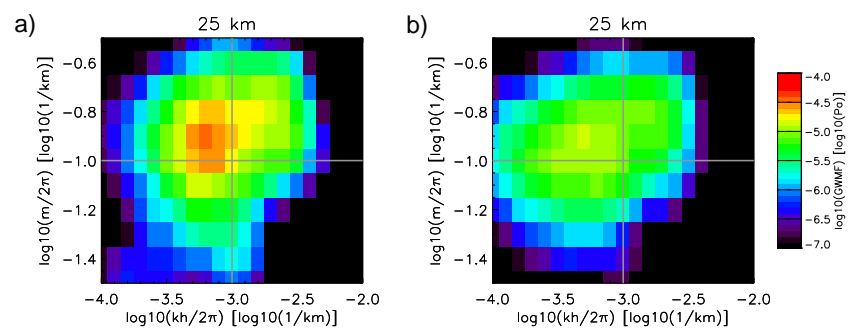

Figure B1. Gravity wave spectrum for period 1, $25 \mathrm{~km}$ altitude, calculated from ECMWF data. The left panel shows the same spectrum as given in Fig. 8e, the right panel shows the spectrum after application of the observational filter. The following differences can be observed: (1) the intensity is generally reduced by roughly a factor of 2, (2) for short horizontal and short vertical wavelengths the reduction is even much stronger and (3) for very long horizontal wavelength some GWMF is added due to the projection of the wavelength on the tangent point track. Black color indicates no wave events in the respective bin.

observational filter therefore requires the orbit-geometry of the considered satellite as well as details of the observation modes and retrievals, i.e., the inversion process from measured radiances to temperature. The observational filter can be applied to any data set which fully characterizes individual waves in terms of amplitudes and the 3-D wave vector such as ray tracing results or 3-D sinusoidal fits.
In Fig. B1 we compare the data for period 1, $25 \mathrm{~km}$ altitude and show spectra as analyzed from ECMWF and after application of the observational filter to these data. The main effects are: the total intensity is reduced by about a factor of 2 . The spectral shape is only slightly modified. Gravity waves with short vertical and short horizontal wavelengths are more strongly reduced than GWs on average. Because of the projection of the horizontal wavelength on the tangent-point track, GWMF appears at longer horizontal wavelengths. The wavelengths contained in ECMWF are too long in order to show significant aliasing effects.

Due to the combined effects, the observational filter enhances the bias of the ECMWF distribution showing overly long horizontal wavelengths; even in the original data, the peak of GWMF from ECMWF is at much longer horizontal wavelengths than for the HIRDLS observations. The application of the observational filter generates a distribution such as HIRDLS would observe if ECMWF data were real. The peak of GWMF in HIRDLS-like ECMWF data is shifted to even longer horizontal wavelengths increasing the discrepancies. 
Acknowledgements. The work was supported in part by ESA through the study "Observation of Gravity Waves from Space" (CN/22561/09/NL/AF) in support of the ESA Earth Explorer 7 candidate PREMIER. SDE's research was supported by the Office of Naval Research. We thank Jörg Langen for many helpful comments made during the study. The authors want to thank two anonymous reviewers for their constructive comments and suggestions, and the editor William Lahoz for his patient and thorough reading of the manuscript. Both helped greatly to improve the presentation of the material.

The service charges for this open access publication

have been covered by a Research Centre of the

Helmholtz Association.

Edited by: W. Lahoz

\section{References}

Alexander, M. J. and Barnet, C. D.: Using satellite observations to constrain gravity wave parameterizations for global models, J. Atmos. Sci., 64, 1652-1665, 2007.

Alexander, M. J. and Ortland, D. A.: Equatorial waves in High Resolution Dynamics Limb Sounder (HIRDLS) data, J. Geophys. Res., 115, D24111, doi:10.1029/2010JD014782, 2010.

Alexander, M. J. and Rosenlof, K. H.: Gravity-wave forcing in the stratosphere: observational constraints from the Upper Atmosphere Research Satellite and implications for parameterization in global models, J. Geophys. Res., 108, 4597, doi:10.1029/2003JD003373, 2003.

Alexander, M. J., Gille, J., Cavanaugh, C., Coffey, M., Craig, C., Dean, V., Eden, T., Francis, G., Halvorson, C., Hannigan, J., Khosravi, R., Kinnison, D., Lee, H., Massie, S., and Nardi, B.: Global estimates of gravity wave momentum flux from High Resolution Dynamics Limb Sounder (HIRDLS) observations, J. Geophys. Res., 113, D15S18, doi:10.1029/2007JD008807, 2008.

Alexander, M. J., Geller, M., McLandress, C., Polavarapu, S., Preusse, P., Sassi, F., Sato, K., Eckermann, S., Ern, M., Hertzog, A., Kawatani, Y., Pulido, M., Shaw, T. A., Sigmond, M., Vincent, R., and Watanabe, S.: Recent developments in gravitywave effects in climate models and the global distribution of gravity-wave momentum flux from observations and models, Q. J. Roy. Meteor. Soc., 136, 1103-1124, doi:10.1002/qj.637, 2010.

Bacmeister, T. J., Eckermann, S. D., Newman, P. A., Lait, L., Chan, K. R., Loewenstein, M., Porffitt, M. H., and Gary, B. L.: Stratospheric horizontal wavenumber spectra of winds, potential temperature and atmospheric tracers observed by high-altitude aircraft, J. Geophys. Res., 101, 9441-9470, doi:10.1029/95JD03835, 1996.

Bechtold, P., Köhler, M., Jung, T., Doblas-Reyes, F., Leutbecher, M., Rodwell, M., Vitart, F., and Balsamo, G.: Advances in simulating atmospheric variability with the ECMWF model: from synoptic to decadal time-scales, Q. J. Roy. Meteor. Soc., 134, 1337-1351, 2008.

Becker, E. and Schmitz, G.: Climatological effects of orography and land-sea heating contrasts on the gravity wave-driven circulation of the mesosphere, J. Atmos. Sci., 60, 103-118, doi:10.1175/1520-0469(2003)060<0103:CEOOAL>2.0.CO;2, 2003.
Beres, J. H., Garcia, R. R., Boville, B. A., and Sassi, F.: Implementation of a gravity wave source spectrum parameterization dependent on the properties of convection in the Whole Atmosphere Community Climate Model (WACCM), J. Geophys. Res., 110, D10108, doi:10.1029/2004JD005504, 2005.

Butchart, N., Cionni, I., Eyring, V., Shepherd, T. G., Waugh, D. W., Akiyoshi, H., Austin, J., Brühl, C., Chipperfield, M. P., Cordero, E., Dameris, M., Deckert, R., Dhomse, S., Frith, S. M., Garcia, R. R., Gettelman, A., Giorgetta, M. A., Kinnison, D. E., Li, F., Mancini, E., McLandress, C., Pawson, S., Pitari, G., Plummer, D. A., Rozanov, E., Sassi, F., Scinocca, J. F., Shibata, K., Steil, B., and Tian, W.: Chemistry-climate model simulations of twenty-first century stratospheric climate and circulation changes, J. Climate, 23, 5349-5374, 2010.

Charron, M. and Manzini, E.: Gravity waves from fronts: parameterization and middle atmosphere response in a general circulation model, J. Atmos. Sci., 59, 923-941, 2002.

Choi, H.-J. and Chun, H.-Y.: Effects of convective gravity wave drag in the Southern Hemisphere winter stratosphere, J. Atmos. Sci., 70, 2120-2136, doi:10.1175/JAS-D-12-0238.1, 2013.

Choi, H.-J., Chun, H.-Y., and Song, I.-S.: Gravity wave temperature variance calculated using the ray-based spectral parameterization of convective gravity waves and its comparison with Microwave Limb Sounder observations, J. Geophys. Res., 114, D08111, doi:10.1029/2008JD011330, 2009.

Collis, S., Protat, A., May, P. T., and Williams, C.: Statistics of Storm Updraft Velocities from TWP-ICE Including Verification with Profiling Measurements, J. Appl. Met. Clim., 52, 19091922, doi:10.1175/JAMC-D-12-0230.1, 2013.

Del Genio, A. D., Wu, J., and Chen, Y.: Characteristics of Mesoscale Organization in WRF Simulations of Convection during TWP-ICE, J. Clim., 25, 5666-5688, doi:10.1175/JCLI-D-1100422.1, 2012.

Dewan, E. M., Picard, R. H., O’Neil, R. R., Gardiner, H. A., Gibson, J., Mill, J. D., Richards, E., Kendra, M., and Gallery, W. O.: MSX satellite observations of thunderstorm-generated gravity waves in mid-wave infrared images of the upper stratosphere, Geophys. Res. Lett., 25, 939-942, 1998.

Dunkerton, T. J.: The role of gravity waves in the quasi-biennial oscillation, J. Geophys. Res., 102, 26053-26076, 1997.

Eckermann, S. D. and Preusse, P.: Global measurements of stratospheric mountain waves from space, Science, 286, 1534-1537, 1999.

Eckermann, S. D., Wu, D. L., Doyle, J. D., Burris, J. F., McGee, T. J., Hostetler, C. A., Coy, L., Lawrence, B. N., Stephens, A., McCormack, J. P., and Hogan, T. F.: Imaging gravity waves in lower stratospheric AMSU-A radiances, Part 2: Validation case study, Atmos. Chem. Phys., 6, 3343-3362, doi:10.5194/acp-6-3343-2006, 2006.

Eidmann, G., Offermann, D., Jarisch, M., Preusse, P., Eckermann, S. D., and Schmidlin, F. J.: Horizontal temperature variability in the stratosphere: global variations inferred from CRISTA data, Adv. Space Res., 27, 1641-1646, 2001.

Ern, M. and Preusse, P.: The contribution of equatorial Kelvin waves to the QBO wind reversal in the stratosphere, Geophys. Res. Lett., 36, L21801, doi:10.1029/2009GL040493, 2009.

Ern, M. and Preusse, P.: Gravity wave momentum flux spectra observed from satellite in the summertime subtropics: impli- 
cations for global modeling, Geophys. Res. Lett., 39, L15810, doi:10.1029/2012GL052659, 2012.

Ern, M., Preusse, P., Alexander, M. J., and Warner, C. D.: Absolute values of gravity wave momentum flux derived from satellite data, J. Geophys. Res., 109, D20103, doi:10.1029/2004JD004752, 2004.

Ern, M., Preusse, P., and Warner, C. D.: Some experimental constraints for spectral parameters used in the Warner and McIntyre gravity wave parameterization scheme, Atmos. Chem. Phys., 6, 4361-4381, doi:10.5194/acp-6-4361-2006, 2006.

Ern, M., Preusse, P., Krebsbach, M., Mlynczak, M. G., and Russell III, J. M.: Equatorial wave analysis from SABER and ECMWF temperatures, Atmos. Chem. Phys., 8, 845-869, doi:10.5194/acp-8-845-2008, 2008.

Ern, M., Preusse, P., Gille, J. C., Hepplewhite, C. L., Mlynczak, M. G., Russell III, J. M., and Riese, M.: Implications for atmospheric dynamics derived from global observations of gravity wave momentum flux in stratosphere and mesosphere, J. Geophys. Res., 116, D19107, doi:10.1029/2011JD015821, 2011.

Ern, M., Preusse, P., Kalisch, S., Kaufmann, M., and Riese, M.: Role of gravity waves in the forcing of quasi two-day waves in the mesosphere: an observational study, J. Geophys. Res.-Atmos., 118, 3467-3485, doi:10.1029/2012JD018208, 2013.

Ern, M., Ploeger, F., Preusse, P., Gille, J. C., Gray, L. J., Kalisch, S., Mlynczak, M. G., Russell III, J. M., and Riese, M.: Interaction of gravity waves with the QBO: a satellite perspective, J. Geophys. Res.-Atmos., 119, 2329-2355, doi:10.1002/2013JD020731, 2014.

Fetzer, E. J. and Gille, J. C.: Gravity wave variances in LIMS temperatures, I, variability and comparison with background winds, J. Atmos. Sci., 51, 2461-2483, 1994.

Fovell, R., Durran, D., and Holton, J. R.: Numerical simulations of convectively generated stratospheric gravity waves, J. Atmos. Sci., 49, 1427-1442, 1992.

Fritts, D. and Alexander, M.: Gravity wave dynamics and effects in the middle atmosphere, Rev. Geophys., 41, 1003, doi:10.1029/2001RG000106, 2003.

Fröhlich, K., Schmidt, T., Ern, M., Preusse, P., de la Torre, A., Wickert, J., and Jacobi, C.: The global distribution of gravity wave energy in the lower stratosphere derived from GPS data and gravity wave modelling: attempt and challenges, J. Atmos. Sol.-Terr. Phys., 69, 2238-2248, doi:10.1016/j.jastp.2007.07.005, 2007.

Gardner, C. S., Hostetler, C. A., and Franke, S. J.: Gravity wave models for the horizontal wave number spectra of atmospheric velocity and density fluctuations, J. Geophys. Res., 98, 35-49, 1993.

Geller, M. A., Alexander, M. J., Love, P. T., Bacmeister, J., Ern, M., Hertzog, A., Manzini, E., Preusse, P., Sato, K., Scaife, A. A., and Zhou, T.: A comparison between gravity wave momentum fluxes in observations and climate models, J. Climate, 26, 6383-6405, doi:10.1175/JCLI-D-12-00545.1, 2013.

Griffiths, M. and Reeder, M.: Stratospheric inertia-gravity waves generated in a numerical model of frontogenesis .1. Model solutions, Quart. J. Roy. Meteorol. Soc., 122, 1153-1174, doi:10.1002/qj.49712253307, 1996.

Guest, F., Reeder, M., Marks, C., and Karoly, D.: Inertia-gravity waves observed in the lower stratosphere over Macquarie Island, J. Atmos. Sci., 57, 737-752, 2000.
Hamilton, K., Wilson, R. J., and Hemler, R. S.: Middle atmosphere simulated with high vertical and horizontal resolution versions of a GCM: improvements in the cold pole bias and generation of a QBO-like oscillation in the tropics, J. Atmos. Sci., 56, 38293846, 1999.

Hendricks, E. A., Doyle, J. D., Eckermann, S. D., Jiang, Q., and Reinecke, P. A.: What is the source of the stratospheric gravity wave belt in austral winter?, J. Atmos. Sci., 71, 1583-1592, doi:10.1175/JAS-D-13-0332.1, 2014.

Hertzog, A., Souprayen, C., and Hauchecorne, A.: Observation and backward trajectory of an inertio-gravity wave in the lower stratosphere, Ann. Geophys., 19, 1141-1155, 2001, http://www.ann-geophys.net/19/1141/2001/.

Hertzog, A., Vial, F., Mechoso, C. R., Basdesavant, C., and Cocquerez, P.: Quasi-Lagrangian measurements in the lower stratosphere reveal an energy peak associated with near-inertial waves, Geophys. Res. Lett., 29, 1229, doi:10.1029/2001GL014083, 2002.

Hertzog, A., Boccara, G., Vincent, R. A., Vial, F., and Cocquerez, P.: Estimation of gravity wave momentum flux and phase speeds from quasi-Lagrangian stratospheric balloon flights, Part II: Results from the Vorcore campaign in Antarctica, J. Atmos. Sci. 65, 3056-3070, doi:10.1175/2008JAS2710.1, 2008.

Hertzog, A., Alexander, M. J., and Plougonven, R.: On the Intermittency of Gravity Wave Momentum Flux in the Stratosphere, J. Atmos. Sci., 69, 3433-3448, doi:10.1175/JAS-D-12-09.1, 2012.

Hines, C. O.: Doppler-spread parameterization of gravity-wave momentum deposition in the middle atmosphere, Part 1: Basic formulation, J. Atmos. Sol.-Terr. Phys., 59, 371-386, 1997.

Hoffmann, L., Xue, X., and Alexander, M. J.: A global view of stratospheric gravity wave hotspots located with Atmospheric Infrared Sounder observations, J. Geophys. Res.-Atmos., 118, 416-434, doi:10.1029/2012JD018658, 2013.

Jewtoukoff, V., Plougonven, R., and Hertzog, A.: Gravity waves generated by deep tropical convection: estimates from balloon observations and mesoscale simulations, J. Geophys. Res.Atmos., 118, 9690-9707, doi:10.1002/jgrd.50781, 2013.

Jiang, J., Eckermann, S., Wu, D., and Ma, J.: A search for mountain waves in MLS stratospheric limb radiances from the winter Northern Hemisphere: data analysis and global mountain wave modeling, J. Geophys. Res.-Atmos., 109, D03107, doi:10.1029/2003JD003974, 2004a.

Jiang, J., Wang, B., Goya, K., Hocke, K., Eckermann, S., Ma, J., Wu, D., and Read, W.: Geographical distribution and interseasonal variability of tropical deep convection: UARS MLS observations and analyses, J. Geophys. Res.-Atmos., 109, D03111, doi:10.1029/2003JD003756, 2004b.

Jiang, J. H., Wu, D. L., and Eckermann, S. D.: Upper Atmosphere Research Satellite (UARS) MLS observations of mountain waves over the Andes, J. Geophys. Res., 107, 8273, doi:10.1029/2002JD002091, 2002.

Joly, A., Jorgensen, D., Shapiro, M., Thorpe, A., Bessemoulin, P., Browning, K., Cammas, J., Chalon, J., Clough, S., Emanuel, K., Eymard, L., Gall, R., Hildebrand, P., Langland, R. Lemaitre, Y., Lynch, P., Moore, J., Persson, P., Snyder, C., and Wakimoto, R.: The Fronts and Atlantic Storm-Track Experiment (FASTEX): Scientific objectives and experimental design, Bull. Amer. Meteor. Soc., 78, 1917-1940, doi:10.1175/15200477(1997)078<1917:TFAAST>2.0.CO;2, 1997. 
Jung, T., Balsamo, G., Bechtold, P., Beljaars, A., Köhler, M., Miller, M., Morcrette, J.-J., Orr, A., Rodwell, M., and Tompkins, A.: The ECMWF model climate: recent progress through improved physical parametrizations, Q. J. Roy. Meteor. Soc., 136, 1145-1160, 2010.

Kalisch, S., Preusse, P., Ern, M., Eckermann, S. D., and Riese, M.: Differences in gravity wave drag between realistic oblique and assumed vertical propagation, J. Geophys. Res.-Atmos., 119, 10081-10099, doi:10.1002/2014JD021779, 2014.

Kawatani, Y., Sato, K., Dunkerton, T. J., Watanabe, S., Miyahara, S., and Takahashi, M.: The roles of equatorial trapped waves and three-dimensionally propagating gravity waves in driving the quasibiennial oscillation, Part I: zonal mean wave forcing, J. Atmos. Sci., 67, 963-980, doi:10.1175/2009JAS3222.1, 2010.

Kim, S.-Y., Chun, H.-Y., and Baik, J.-J.: Sensitivity of typhooninduced gravity waves to cumulus parameterizations, Geophys. Res. Lett., 34, L15814, doi:10.1029/2007GL030592, 2007.

Kim, S.-Y., Chun, H.-Y., and Wu, D. L.: A study on stratospheric gravity waves generated by typhoon Ewiniar: numerical simulations and satellite observations, J. Geophys. Res., 114, D22104, doi:10.1029/2009JD011971, 2009.

Kim, Y.-H., Chun, H.-Y., Preusse, P., Ern, M., and Kim, S.-Y.: Gravity wave reflection and its influence on the consistency of temperature- and wind-based momentum fluxes simulated above Typhoon Ewiniar, Atmos. Chem. Phys., 12, 10787-10795, doi:10.5194/acp-12-10787-2012, 2012.

Kim, Y.-J., Eckermann, S. D., and Chun, H.-Y.: An overview of the past, present and future of gravity-wave drag parameterization for numerical climate and weather prediction models - survey article, Atmos. Ocean, 41, 65-98, 2003.

Krebsbach, M. and Preusse, P.: Spectral analysis of gravity wave activity in SABER temperature data, Geophys. Res. Lett., 34, L03814, doi:10.1029/2006GL028040, 2007.

Lane, T. P. and Knievel, J. C.: Some effects of model resolution on simulated gravity waves generated by deep mesoscale convection, J. Atmos. Sci., 62, 3408-3419, 2005.

Lane, T. P. and Sharman, R. D.: Gravity wave breaking, secondary wave generation, and mixing above deep convection in a threedimensional cloud model, Geophys. Res. Lett., 33, L23813, doi:10.1029/2006GL027988, 2006.

Lane, T. P., Reeder, M. J., and Clark, T. L.: Numerical modeling of gravity wave generation by deep tropical convection, J. Atmos. Sci., 58, 1249-1274, 2001.

Lange, M. and Jacobi, C.: Analysis of gravity waves from radio occultation measurements, Springer Berlin, 479-484, 2003.

Leena, P., Venkat Ratnam, M., and Krishna Murthy, B.: Inertia gravity wave characteristics and associated fluxes observed using five years of radiosonde measurements over a tropical station, J. Atmos. Sol.-Terr. Phys., 84-85, 37-44, doi:10.1016/j.jastp.2012.05.004, 2010.

Lehmann, C. I., Kim, Y.-H., Preusse, P., Chun, H.-Y., Ern, M., and Kim, S.-Y.: Consistency between Fourier transform and smallvolume few-wave decomposition for spectral and spatial variability of gravity waves above a typhoon, Atmos. Meas. Tech., 5, 1637-1651, doi:10.5194/amt-5-1637-2012, 2012.

Lighthill, M. J.: Waves in Fluids, Cambridge University Press, Cambridge, 504 pp., 1978.
Lott, F. and Miller, M. J.: A new subgrid scale orographic drag parameterization: its formulation and testing, Q. J. Roy. Meteor. Soc., 123, 101-127, 1997.

Manzini, E. and McFarlane, N. A.: The effect of varying the source spectrum of a gravity wave parameterization in a middle atmosphere general circulation model, J. Geophys. Res., 103, $31523-$ 31539, 1998.

Marks, C. J. and Eckermann, S. D.: A three-dimensional nonhydrostatic ray-tracing model for gravity waves: formulation and preliminary results for the middle atmosphere, J. Atmos. Sci., 52, 1959-1984, 1995.

McFarlane, N. A.: The effect of orographically excited gravity wave drag on the general circulation of the lower stratosphere and troposphere, J. Atmos. Sci., 44, 1775-1800, 1987.

McLandress, C. and Scinocca, J. F.: The GCM response to current parameterizations of nonorographic gravity wave drag, J. Atmos. Sci., 62, 2394-2413, 2005.

McLandress, C. and Shepherd, T. G.: Simulated anthropogenic changes in the Brewer-Dobson circulation, including its extension to high latitudes, J. Climate, 22, 1516-1540, doi:10.1175/2008JCLI2679.1, 2009.

Medvedev, A. S. and Klaassen, G. P.: Parameterization of gravity wave momentum deposition based on nonlinear wave interactions: basic formulation and sensitivity tests, J. Atmos. Sol.-Terr. Phys., 62, 1015-1033, 2000.

Moldovan, H., Lott, F., and Teitelbaum, H.: Wave breaking and critical levels for propagating inertio-gravity waves in the lower stratosphere, Quart. J. Roy. Meteorol. Soc., 128, 713-732, doi:10.1256/003590002321042162, 2002.

Orr, A., Bechtold, P., Scinocca, J., Ern, M., and Janiskova, M.: Improved middle atmosphere climate and forecasts in the ECMWF model through a nonorographic gravity wave drag parameterization, J. Climate, 23, 5905-5926, 2010.

O'Sullivan, D. and Dunkerton, T. J.: Generation of inertia-gravity waves in a simulated life cycle of baroclinic instability, J. Atmos. Sci., 52, 3695-3716, 1995.

Persson, A. and Grazzini, F.: User Guide to ECMWF forecast products, ECMWF web page, Meteorol. Bull., M3.2, Wuppertal, 161 pp., 2005.

Pfister, L., Scott, S., Loewenstein, M., Brown, S., and Legg, M.: Mesoscale disturbances in the tropical stratosphere excited by convection: observations and effects on the stratospheric momentum budget, J. Atmos. Sci., 50, 1058-1075, 1993.

Plougonven, R. and Teitelbaum, H.: Comparison of a largescale inertia-gravity wave as seen in the ECMWF analyses and from radiosondes, Geophys. Res. Lett., 30, 1954, doi:10.1029/2003GL017716, 2003.

Plougonven, R. and Zhang, F.: Internal gravity waves from atmospheric jets and fronts, Rev. Geophys., 52, 33-76, doi:10.1002/2012RG000419, 2014.

Plougonven, R., Hertzog, A., and Guez, L.: Gravity waves over Antarctica and the Southern Ocean: consistent momentum fluxes in mesoscale simulations and stratospheric balloon observations, Q. J. Roy. Meteor. Soc., 139, 101-118, doi:10.1002/qj.1965, 2013.

Plougonven, R., Teitelbaum, H., and Zeitlin, V.: Inertia-gravity wave generation by the tropospheric mid-latitude jet as given by the FASTEX radiosoundings, J. Geophys. Res., 108, 4686, doi:10.1029/2003JD003535, 2003. 
Preusse, P.: Satellitenmessungen von Schwerewellen in der mittleren Atmosphäre mit CRISTA, Ph.D. thesis, Wuppertal University, 9, available at: http://elpub.bib.uni-wuppertal.de/servlets/ DerivateServlet/Derivate-412/d080111.pdf (last access: 9 May 2014), 2001.

Preusse, P., Schaeler, B., Bacmeister, J., and Offermann, D.: Evidence for gravity waves in CRISTA temperatures, Adv. Space Res., 24, 1601-1604, 1999.

Preusse, P., Eidmann, G., Eckermann, S. D., Schaeler, B., Spang, R., and Offermann, D.: Indications of convectively generated gravity waves in CRISTA temperatures, Adv. Space Res., 27, 16531658, 2001.

Preusse, P., Doernbrack, A. D., Eckermann, S. D., Riese, M., Schaeler, B., Bacmeister, J., Broutman, D., and Grossmann, K. U.: Space based measurements of stratospheric mountain waves by CRISTA, 1 . Sensitivity, analysis method and a case study, J. Geophys. Res., 107, 8178, doi:10.1029/2001JD000699, 2002

Preusse, P., Ern, M., Eckermann, S. D., Warner, C. D., Picard, R. H., Knieling, P., Krebsbach, M., Russel III, J. M., Mlynczak, M. G., Mertens, C. J., and Riese, M.: Tropopause to mesopause gravity waves in August: measurement and modeling, J. Atmos. Sol.Terr. Phys., 68, 1730-1751, 2006.

Preusse, P., Eckermann, S. D., Ern, M., Oberheide, J., Picard, R. H., Roble, R. G., Riese, M., Russell III, J. M., and Mlynczak, M. G.: Global ray tracing simulations of the SABER gravity wave climatology, J. Geophys. Res., 114, D08126, doi:10.1029/2008JD011214, 2009a.

Preusse, P., Schroeder, S., Hoffmann, L., Ern, M., Friedl-Vallon, F., Ungermann, J., Oelhaf, H., Fischer, H., and Riese, M.: New perspectives on gravity wave remote sensing by spaceborne infrared limb imaging, Atmos. Meas. Tech., 2, 299-311, doi:10.5194/amt-2-299-2009, 2009b.

Reeder, M. and Griffiths, M.: Stratospheric inertia-gravity waves generated in a numerical model of frontogenesis .2. Wave sources, generation mechanisms and momentum fluxes, Quart. J. Roy. Meteorol. Soc., 122, 1175-1195, doi:10.1002/qj.49712253308, 1996.

Ricciardulli, L. and Garcia, R. R.: The excitation of equatorial waves by deep convection in the NCAR Community Climate Model (CCM3), J. Atmos. Sci., 57, 3461-3487, 2000.

Richter, J. H., Sassi, F., and Garcia, R. R.: Toward a physically based gravity wave source parameterization in a general circulation model, J. Atmos. Sci., 67, 136-156, 2010.

Riese, M., Friedl-Vallon, F., Spang, R., Preusse, P., Schiller, C., Hoffmann, L., Konopka, P., Oelhaf, H., von Clarmann, T., and Höpfner, M.: GLObal limb Radiance Imager for the Atmosphere (GLORIA): scientific objectives, Adv. Space Res., 36, 989-995, 2005.

Salby, M. L. and Garcia, R. R.: Transient response to localized episodic heating in the tropics, Part I: excitation and short-time near-field behavior, J. Atmos. Sci., 44, 458-498, 1987.

Sato, K., Watanabe, S., Kawatani, Y., Tomikawa, Y., Miyazaki, K., and Takahashi, M.: On the origins of mesospheric gravity waves, Geophys. Res. Lett., 36, L19801, doi:10.1029/2009GL039908, 2009.

Scaife, A. A., Athanassiadou, M., Andrews, M., Arribas, A., Baldwin, M., Dunstone, N., Knight, J., MacLachlan, C., Manzini, E., ller, W. A. M., Pohlmann, H., Smith, D., Stockdale, T., and Williams, A.: Predictability of the Quasi-Biennial Oscillation and its northern winter teleconnection on seasonal to decadal timescales, Geophys. Res. Lett., 41, 1752-1758, doi:10.1002/2013GL059160, 2014.

Schroeder, S., Preusse, P., Ern, M., and Riese, M.: Gravity waves resolved in ECMWF and measured by SABER, Geophys. Res. Lett., 36, L10805, doi:10.1029/2008GL037054, 2009.

Senf, F. and Achatz, U.: On the impact of middle-atmosphere thermal tides on the propagation and dissipation of gravity waves, J. Geophys. Res.-Atmos., 116, D24110, doi:10.1029/2011JD015794, 2011.

Shutts, G. J. and Vosper, S. B.: Stratospheric gravity waves revealed in NWP model forecasts, Quart. J. Roy. Meteorol. Soc., 137, 303-317, doi:10.1002/qj.763, 2011.

Skamarock, W. C.: Evaluating mesoscale NWP models using kinetic energy spectra, Mon. Weather Rev., 132, 3019-3032, 2004.

Skamarock, W. C., Klemp, J. B., Dudhia, J., Gill, D. O., Barker, D. M., Wang, W., and Power, J. G.: A description of the Advanced Research WRF Version 2, Tech. rep., NCAR, Boulder, USA, 2005.

Song, I.-S. and Chun, H.-Y.: A lagrangian spectral parameterization of gravity wave drag induced by cumulus convection, J. Atmos. Sci., 65, 1204-1224, 2008.

Song, I.-S., Chun, H.-Y., Garcia, R. R., and Boville, B. A.: Momentum flux spectrum of convectively forced internal gravity waves and its application to gravity wave drag parameterization, Part II: Impacts in a GCM (WACCM), J. Atmos. Sci., 64, 2286-2308, 2007.

Tateno, S. and Sato, K.: A Study of Inertia-Gravity Waves in the Middle Stratosphere Based on Intensive Radiosonde Observations, J. Met. Soc. Japan, 86, 719-732, doi:10.2151/jmsj.86.719, 2008.

Taylor, M. J. and Hapgood, M. A.: Identification of a thunderstorm as a source of short period gravity waves in the upper atmospheric nightglow emissions, Planet. Space Sci., 36, 975-985, 1988.

Uccellini, L. W. and Koch, S. E.: The Synoptic Setting and Possible Energy Sources for Mesoscale Wave Disturbances, Month. Weath. Rev., 115, 721-729, 1987.

Warner, C. D. and McIntyre, M. E.: Toward an ultra-simple spectral gravity wave parameterization for general circulation models, Earth Plantes Space, 51, 475-484, 1999.

Watanabe, S.: Constraints on a non-orographic gravity wave drag paremterization using a gravity wave resolving general circulation model, Sci. Online Lett. Atmos., 4, 61-64, 2008.

Wright, C. J. and Gille, J. C.: HIRDLS observations of gravity wave momentum fluxes over the monsoon regions, J. Geophys. Res., 116, D12103, doi:10.1029/2011JD015725, 2011.

$\mathrm{Wu}, \mathrm{D}$. L. and Eckermann, S. D.: Global gravity variances from Aura MLS: characteristics and interpretation, J. Atmos. Sci., 65, 3695-3718, 2008.

Wu, D. L. and Waters, J. W.: Observations of gravity waves with the UARS Microwave Limb Sounder, in: Gravity Wave Processes and Their Parameterization in Global Climate Models, edited by: Hamilton, K., Springer Verlag, New York, 103-120, 1997.

Wu, J., Del Genio, A. D., Yao, M.-S., and Wolf, A. B.: WRF and GISS SCM simulations of convective updraft properties during TWP-ICE, J. Geophys. Res. Atmos., 114, D04206, doi:10.1029/2008JD010851, 2009. 
Yamashita, C., Liu, H.-L., and Chu, X.: Gravity wave variations during the 2009 stratospheric sudden warming as revealed by ECMWF-T799 and observations, Geophys. Res. Lett., 37, L22806, doi:10.1029/2010GL045437, 2010.
Zuelicke, C. and Peters, D.: Simulation of inertia-gravity waves in a poleward-breaking Rossby wave, J. Atmos. Sci., 63, 3253-3276, doi:10.1175/JAS3805.1, 2006. 